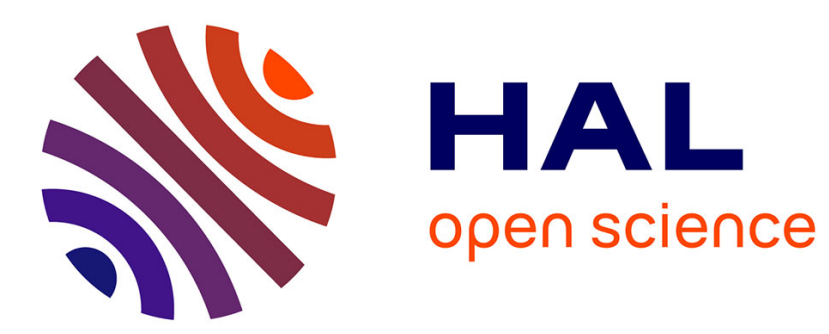

\title{
A description of the composite elastic modulus of multilayer coated systems
}

E.S. Puchi-Cabreraa, M.H. Staia, Alain Iost

\section{To cite this version:}

E.S. Puchi-Cabreraa, M.H. Staia, Alain Iost. A description of the composite elastic modulus of multilayer coated systems. Thin Solid Films, 2015, 583, pp.177-193. 10.1016/j.tsf.2015.02.078 . hal01169478

\section{HAL Id: hal-01169478 \\ https://hal.science/hal-01169478}

Submitted on 29 Jun 2015

HAL is a multi-disciplinary open access archive for the deposit and dissemination of scientific research documents, whether they are published or not. The documents may come from teaching and research institutions in France or abroad, or from public or private research centers.
L'archive ouverte pluridisciplinaire HAL, est destinée au dépôt et à la diffusion de documents scientifiques de niveau recherche, publiés ou non, émanant des établissements d'enseignement et de recherche français ou étrangers, des laboratoires publics ou privés. 


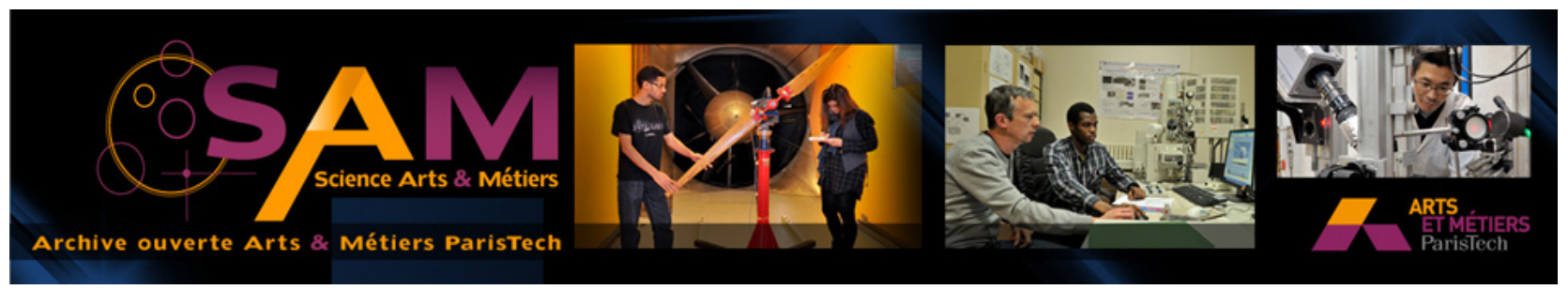

Science Arts \& Métiers (SAM)

is an open access repository that collects the work of Arts et Métiers ParisTech researchers and makes it freely available over the web where possible.

This is an author-deposited version published in: http://sam.ensam.eu Handle ID: .http://hdl.handle.net/10985/9658

\section{To cite this version :}

E.S. PUCHI-CABRERAA, M.H. STAIA, Alain IOST - A description of the composite elastic modulus of multilayer coated systems - Thin Solid Films - Vol. 583, p.177-193 - 2015 


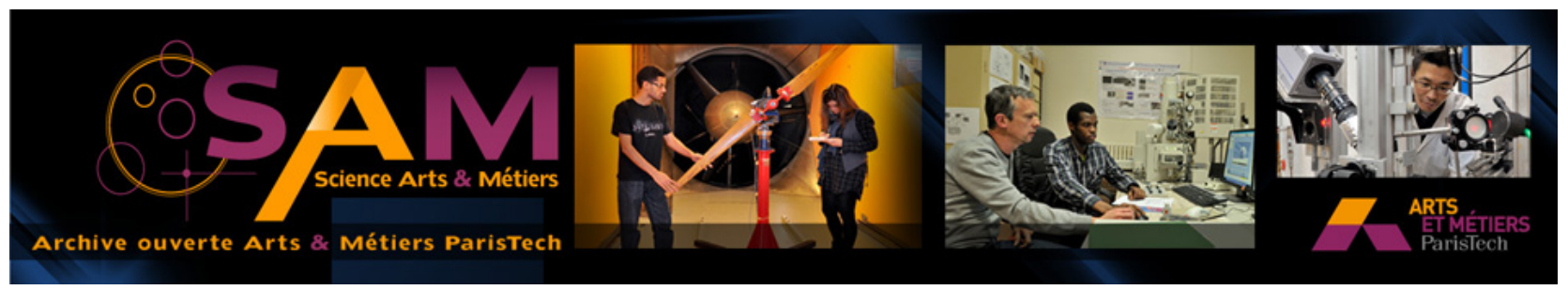

Science Arts \& Métiers (SAM)

is an open access repository that collects the work of Arts et Métiers ParisTech researchers and makes it freely available over the web where possible.

This is an author-deposited version published in: http://sam.ensam.eu Handle ID: .http://hdl.handle.net/null

\section{To cite this version :}

E.S. PUCHI CABRERA, M.H. STAIA, Alain IOST - A description of the composite elastic modulus of multilayer coated systems - Thin Solid Films - Vol. 583, p.177-193 - 2015 


\title{
A description of the composite elastic modulus of multilayer coated systems
}

\author{
E.S. Puchi-Cabrera ${ }^{\mathrm{a}, \mathrm{b}, \mathrm{c}, *}$, M.H. Staia ${ }^{\mathrm{a}, \mathrm{b}, \mathrm{d}}$, A. Iost $^{\mathrm{d}}$ \\ a School of Metallurgical Engineering and Materials Science, Faculty of Engineering, Universidad Central de Venezuela, 47885, Los Chaguaramos, Caracas 1040, Venezuela \\ b Venezuelan National Academy for Engineering and Habitat, Palacio de las Academias, 1723, Caracas 1010, Venezuela \\ ' Université Lille Nord de France, USTL, LML, CNRS, UMR 8107, F-59650 Villeneuve d'Ascq, France \\ ${ }^{\mathrm{d}}$ Arts et Métiers ParisTech, MSMP, Centre de Lille, 8, Boulevard Louis XIV, 59000 Lille Cedex, France
}

Keywords:

Elastic modulus

Penetration depth

Multilayer coatings

Nanoindentation testing

\begin{abstract}
A B S T R A C T
The evaluation of the elastic response of coated systems under indentation loading represents a crucial issue, which determines the behavior of such systems under tribological applications. Although a number of models have been proposed in the literature for the description of the change in the composite modulus with indentation depth, as well as for the determination of the elastic modulus of monolayer coatings, only few works address the analysis of multilayer coatings. The present work proposes a general methodology, which allows the modification and extension of the models employed in the analysis of monolayer coatings, for the study of the elastic response of multilayer coatings. For this purpose, a number of models have been examined, including those proposed by Gao et al., Menčík et al., Perriot and Barthel, Antunes et al., Korsunsky and Constantinescu, Doerner and Nix, Bec et al. and Bull. The foundation of the advanced formalism is the physically-based concept proposed by Iost et al. for the computation of the volume fraction of each layer in the coating and therefore, of its contribution to the global elastic response under indentation. The modified models are further employed in the analysis of a coated system composed of a 2024-T6 aluminum alloy substrate coated with a multilayer coating of $\mathrm{DLC} / \mathrm{CrC} / \mathrm{CNiPCr} / \mathrm{NiP}$ of approximately $54 \mu \mathrm{m}$ in thickness, as well as, a set of experimental data reported by Bull for a bilayer coated system. It has been shown that the different models analyzed are able to provide a satisfactory description of the experimental data, although the quality of the fit depends on the number of material parameters involved in each model. The mean square error of the fit is employed for conducting a comparison between the models.
\end{abstract}

\section{Introduction}

Multilayer coatings, deposited by means of both chemical vapor deposition (CVD) and physical vapor deposition (PVD) techniques, have been employed for the improvement of hardness, elastic modulus, adhesion strength, toughness, wear resistance, as well as decreasing the friction coefficient of coated systems. Particularly, the increase in hardness and load-bearing capacity brought about by the deposition of such films has been attributed to the presence of interfaces between the different layers, which act as barriers to dislocation motion. Therefore, as the number of such interfaces increases, a concomitant increase in the mechanical properties and performance of the multilayer coated system has been observed [1-12].

\footnotetext{
* Corresponding author at: Université Lille Nord de France, USTL, LML, CNRS, UMR 8107, F-59650 Villeneuve d'Ascq, France.

E-mail addresses: Eli.Puchi@univ-lille1.fr (E.S. Puchi-Cabrera), mhstaia@gmail.com (M.H. Staia), alain.iost@ensam.eu (A. Iost).
}

In general, the assessment of the mechanical behavior of coated systems involving multilayer coatings requires an accurate determination of both hardness and the elastic properties, not only of the multilayer as a whole, but also of the individual layers which compose it. For example, it is widely accepted that the $\mathrm{H}^{3} / \mathrm{E}^{* 2}$ ratio could provide a good indication of the resistance to plastic deformation of the coating and therefore, of its toughness [13,14]. Here $\mathrm{H}$ stands for hardness and $\mathrm{E}^{*}$ represents the plane strain modulus of the film, which is given by $\mathrm{E}^{*}=\mathrm{E} /\left(1-v^{2}\right)$, where $v$ represents the Poisson ratio. In this sense, experience shows that an increase in such a ratio leads not only to the increase in the wear resistance of the coated system, but also an increase in impact resistance $[15,16]$. Therefore, a precise evaluation of the global properties of the multilayer, as well as the individual mechanical properties of each layer would be of utmost importance for designing the performance of such materials in service.

In the case of monolayer coatings, a number of empirical models have been proposed for determining the elastic modulus of the film, $\mathrm{E}_{\mathrm{F}}$, from indentation testing and to ensure that the measured 


\section{Nomenclature}

Arabic symbols

a contact radius

$\mathrm{a}\left(\mathrm{t}_{\mathrm{f}} / \mathrm{h}\right) \quad$ weight function

$\mathrm{a}_{\mathrm{A} 1}\left(\alpha_{\mathrm{A} 1}, \mathrm{t}_{\mathrm{f}} / \mathrm{h}\right)$ weight function in the first model advanced by Antunes et al.

$\mathrm{a}_{\mathrm{A} 2}\left(\mathrm{t}_{\mathrm{f}} / \mathrm{h}\right)$ weight function in the second model advanced by Antunes et al.

$a_{B}\left(t_{f} / h\right)$ weight function in the model advanced by Bull

$a_{B e c}\left(t_{f}, a, h\right)$ weight function in the Bec et al. model

$a_{D N}^{(i)}, a_{D N}\left(\alpha_{D N}, t_{f} / h\right)$ weight function in the Doerner and Nix model

$\mathrm{a}_{\mathrm{G}}\left(\mathrm{t}_{\mathrm{f}} / \mathrm{h}\right)$ weight function in the Gao et al. model

$a_{K C}\left(\beta_{K C}, n_{K C}, t_{f} / h\right)$ weight function in the Korsunsky and Constantinescu model

$\mathrm{a}_{\mathrm{M} 1}\left(\alpha_{\mathrm{M} 1}, \mathrm{t}_{\mathrm{f}} / \mathrm{h}\right)$ weight function in the first model advanced by Menčík et al.

$\mathrm{a}_{\mathrm{M} 2}\left(\alpha_{\mathrm{M} 2}, \mathrm{t}_{\mathrm{f}} / \mathrm{h}\right)$ weight function in the second model advanced by Menčík et al.

$\mathrm{a}_{\mathrm{PB}}\left(\beta_{\mathrm{PB}}, \mathrm{n}_{\mathrm{PB}}, \mathrm{t}_{\mathrm{f}} / \mathrm{h}\right)$ weight function in the Perriot-Barthel model

$\mathrm{b}^{(\mathrm{i})}, \mathrm{b}\left(\mathrm{C}, \mathrm{t}_{\mathrm{f}}, \mathrm{h}\right)$ weight function in the Jönsson-Hogmark model

C $\quad \mathrm{C}^{(\mathrm{i})}$ constants in the Jönsson-Hogmark model

E elastic modulus, GPa

$\mathrm{E}^{*} \quad$ plane strain elastic modulus, GPa

$\mathrm{E}_{\mathrm{C}} \quad$ composite elastic modulus, GPa

$\mathrm{E}_{\mathrm{C} \text { Exp. }} \quad$ experimental values of the composite elastic modulus, $\mathrm{GPa}$

E $_{\mathrm{C}}$ Cal. computed values of the composite elastic modulus, GPa

$\mathrm{E}_{\mathrm{S}} \quad$ substrate elastic modulus, $\mathrm{GPa}$

$\mathrm{E}_{\mathrm{F}} \quad$ elastic modulus of a film, $\mathrm{GPa}$

$\mathrm{h} \quad$ indentation or penetration depth, $\mathrm{nm}$

$\mathrm{h}_{\mathrm{c}} \quad$ contact depth, $\mathrm{nm}$

$\mathrm{h}_{\max } \quad$ maximum penetration depth, $\mathrm{nm}$

$\mathrm{H} \quad$ hardness, GPa

$\mathrm{H}_{\mathrm{C}} \quad$ composite hardness, GPa

$\mathrm{k}_{\mathrm{b}} \quad$ constant in the Bec et al. model, nm

$\mathrm{N} \quad$ number of layers in the multilayer coating

$\mathrm{n}_{\mathrm{b}} \quad$ constant in the Bec et al. model

$\mathrm{N}_{\text {Exp. }} \quad$ number of experimental data points

$\mathrm{n}_{\mathrm{KC}}$ adjustable parameter in the Korsunsky and Constantinescu model

$\mathrm{n}_{\mathrm{PB}} \quad$ adjustable parameter in the Perriot and Barthel model

$\mathrm{N}_{\mathrm{par}} \quad$ number of adjustable parameters in the models

P load, $\mathrm{N}$

$\mathrm{S} \quad$ contact stiffness, $\mathrm{N} \mathrm{m}^{-1}$

$\mathrm{t}_{\mathrm{f}}, \mathrm{t}_{\mathrm{f}}^{(\mathrm{i})} \quad$ coating thickness, $\mathrm{nm}$

$\mathrm{x}_{\mathrm{v}}^{(\mathrm{i})} \quad$ volume fraction of the ith-layer in the multilayer coating

\section{Greek symbols}

$\alpha_{\mathrm{DN}} \quad$ adjustable parameter in the model of Doerner and Nix

$\beta_{\mathrm{KC}}$ adjustable parameter in the Korsunsky and Constantinescu model

$\beta_{\mathrm{PB}} \quad$ adjustable parameter in the Perriot and Barthel model

$\phi, \phi\left(\mathrm{h}, \mathrm{t}_{\mathrm{f}}, v\right)$ weight function in the Gao et al. model

$v \quad$ Poisson ratio

$\Psi \quad$ half-angle of the tip conical indenter at the maximum load

properties are not influenced by the deformation of the substrate. Some of these models, such as those proposed by Gao et al. [17], Menčík et al. [18], Perriot and Barthel [19], Antunes et al. [20] and
Korsunsky and Constantinescu [21], are expressed in terms of a linear law of mixtures of the form:

$\mathrm{E}_{\mathrm{C}}=\mathrm{a}\left(\mathrm{t}_{\mathrm{f}} / \mathrm{h}\right) \mathrm{E}_{\mathrm{F}}+\left[1-\mathrm{a}\left(\mathrm{t}_{\mathrm{f}} / \mathrm{h}\right)\right] \mathrm{E}_{\mathrm{S}}$

or

$\mathrm{E}_{\mathrm{C}}=\left[1-\mathrm{a}\left(\mathrm{t}_{\mathrm{f}} / \mathrm{h}\right)\right] \mathrm{E}_{\mathrm{F}}+\mathrm{a}\left(\mathrm{t}_{\mathrm{f}} / \mathrm{h}\right) \mathrm{E}_{\mathrm{S}}$

A second group of these models, as those proposed by Doerner and Nix [22], Bec et al. [23], Menčík et al. [18], Antunes et al. [20] and more recently by Bull [24,25], have been expressed by assuming the validity of a harmonic law of mixtures, of the form:

$\frac{1}{E_{C}}=\frac{a\left(t_{f} / h\right)}{E_{F}}+\frac{1-a\left(t_{f} / h\right)}{E_{S}}$

or

$\frac{1}{\mathrm{E}_{\mathrm{C}}}=\frac{1-\mathrm{a}\left(\mathrm{t}_{\mathrm{f}} / \mathrm{h}\right)}{\mathrm{E}_{\mathrm{F}}}+\frac{\mathrm{a}\left(\mathrm{t}_{\mathrm{f}} / \mathrm{h}\right)}{\mathrm{E}_{\mathrm{S}}}$.

In the above equations, $\mathrm{E}_{\mathrm{C}}$ represents the composite elastic modulus, $\mathrm{E}_{\mathrm{S}}$ the substrate elastic modulus and $\mathrm{a}\left(\mathrm{t}_{\mathrm{f}} / \mathrm{h}\right)$ a weight function commonly expressed in terms of the coating thickness to indentation depth or coating thickness to contact radius ratio. In some of the models, $\mathrm{a}\left(\mathrm{t}_{\mathrm{f}} / \mathrm{h}\right)$ also involves some adjustable parameters.

On the contrary, the experimental and theoretical work devoted to the determination of the elastic modulus of individual layers in multilayer coatings has been relatively more limited. For example, in the case of bilayer coatings, Whiting et al. [26,27] and Harms et al. [28] employed the so called "vibration reed" method, which allows the computation of the elastic modulus of one layer of the coating from the shift in natural frequency of the beam without and with the second layer.

Chudoba et al. [29], on the other hand, proposed a methodology for determining the elastic properties of bilayer systems from elastic indentation conducted with spherical indenters, together with the modeling of the corresponding force-penetration depth curve. Similarly, Malzbender and Steinbrech [30] presented a set of relationships in order to analyze the mechanical properties of multi-layered composites employing the experimental data derived from bending tests. This approach allows the determination of the unknown thickness or elastic modulus for a layer within a multi-layered composite, provided that the respective properties of all other layers are known.

More recently, López-Puerto and co-workers [31] were able to extend the methodology proposed by Whiting et al. [26,27] and Harms et al. [28], to the analysis of multilayer coatings by developing an integral approach, which allows the computation of the elastic modulus of a single layer in a multilayered system in cantilever configuration, by measuring the natural frequency of the complete multilayered cantilever beam. These authors were able to verify the accuracy of the model by comparing the predicted values of the fundamental frequency with those predicted by a three dimensional finite element model of laminated cantilever beams for systems of three layers composed of two dissimilar metallic films, with thicknesses less than $250 \mathrm{~nm}$, deposited onto a polymeric substrate.

On the other hand, Bull [25] has recently developed an alternative methodology for determining the elastic modulus of a coating on a substrate by means of nanoindentation. The method is based on the load support of a truncated cone of material beneath the indenter. This author has shown that the proposed model can be extended to the analysis of multilayer coatings, which constitutes a critical aspect when compliant coating layers are sandwiched between stiffer layers.

Thus, given the limited research work that has been carried out in order to characterize the elastic mechanical properties of multilayer coatings by means of indentation methods, a strong motivation arises 
to adapt the existing models developed for monolayer coatings to this aim. Therefore, the present work has been carried out in order to propose a simple methodology, which allows the extension of the different models developed for the description of the composite elastic modulus of coated systems encompassing monolayer coatings, for determining the elastic modulus of each of the individual layers, which compose a multilayer coating, as well as describing the composite elastic modulus of such coated systems. The advanced approach is based on the rational computation of the actual volume fraction of each layer in the coating, which contributes to the composite elastic modulus, following the earlier developments of Iost et al. [32] for the description of the composite hardness of multilayer coatings.

\section{Brief review of the different models earlier advanced for the deter- mination of the elastic modulus of monolayer coatings}

Doerner and Nix [22], in their pioneer investigation, first advanced a methodology for the interpretation of depth-sensing indentation data, which allowed the determination of the elastic modulus of thin films from the slope of the unloading of the indentation conducted on the coated system. For this purpose, the above authors proposed an empirical expression for the reciprocal of the unloading slope, $\mathrm{dh} / \mathrm{dP}$, or compliance of the coated system under investigation, of the form:

$$
\begin{aligned}
\frac{\mathrm{dh}}{d P}= & \frac{1}{2 \mathrm{~h}}\left(\frac{\pi}{24.5}\right)^{\frac{1}{2}}\left[\frac{1-\nu_{f}^{2}}{\mathrm{E}_{\mathrm{f}}}\left(1-\mathrm{e}^{-\frac{\alpha_{\mathrm{DN}} \mathrm{t}_{\mathrm{f}}}{h}}\right)+\frac{1-\nu_{\mathrm{s}}^{2}}{\mathrm{E}_{\mathrm{s}}}\left(\mathrm{e}^{-\frac{\alpha_{\mathrm{DN}} \mathrm{t}_{\mathrm{f}}}{\mathrm{h}}}\right)+\frac{1-\nu_{0}^{2}}{\mathrm{E}_{0}}\right] \\
& +\mathrm{b}_{\mathrm{s}} .
\end{aligned}
$$

Accordingly, the composite elastic modulus for the coated system, $\mathrm{E}_{\mathrm{C}}$, would be given by:

$\frac{1}{\mathrm{E}_{\mathrm{C}}}=\frac{1-\mathrm{a}_{\mathrm{DN}}\left(\alpha_{\mathrm{DN}}, \mathrm{t}_{\mathrm{f}} / \mathrm{h}\right)}{\mathrm{E}_{\mathrm{F}}}+\frac{\mathrm{a}_{\mathrm{DN}}\left(\alpha_{\mathrm{DN}}, \mathrm{t}_{\mathrm{f}} / \mathrm{h}\right)}{\mathrm{E}_{\mathrm{S}}}$

where the weight function, $a_{D N}\left(\alpha_{D N}, t_{f} / h\right)$, is expressed as:

$a_{D N}\left(\alpha_{D N}, t_{f} / h\right)=\exp \left(-\alpha_{D N} \frac{t_{f}}{h}\right)$

In the above equations, $\mathrm{h}$ represents the true plastic or penetration depth, $v_{\mathrm{f}}, \mathrm{E}_{\mathrm{f}}, v_{\mathrm{s}}, \mathrm{E}_{\mathrm{s}}$ and $v_{0}, \mathrm{E}_{0}$, the Poisson ratio and elastic modulus of coating, substrate and indenter, respectively, $\mathrm{t}_{\mathrm{f}}$ the coating thickness, $\alpha_{\mathrm{DN}}$ an empirical constant and $b_{\mathrm{s}}$ the intercept corresponding to the bulk substrate.

In a subsequent investigation, Gao et al. [17] analyzed the elastic contact problem of a rigid cylindrical punch indenting a multi-layered linear elastic half space. The results of this analysis were employed to model the unloading phase of a microindentation test of thin films deposited on a substrate. According to this analysis, the composite modulus can be expressed as a simple linear law of mixtures as a function of the film and substrate moduli, of the form:

$\mathrm{E}_{\mathrm{C}}=\mathrm{a}_{\mathrm{G}}\left(\mathrm{t}_{\mathrm{f}} / \mathrm{h}\right) \mathrm{E}_{\mathrm{F}}+\left(1-\mathrm{a}_{\mathrm{G}}\left(\mathrm{t}_{\mathrm{f}} / \mathrm{h}\right)\right) \mathrm{E}_{\mathrm{S}}$

where the weight function $a_{G}\left(t_{f} / h\right)$ would be given by:

$$
\begin{aligned}
\mathrm{a}_{\mathrm{G}}\left(\mathrm{t}_{\mathrm{f}} / \mathrm{h}\right)= & \phi\left(\mathrm{h}, \mathrm{t}_{\mathrm{f}}, v\right)=\frac{2}{\pi} \tan ^{-1}\left(\frac{\mathrm{t}_{\mathrm{f}}}{\mathrm{h} \tan \psi}\right) \\
& +\frac{1}{2 \pi(1-v)}\left\{(1-2 v) \frac{\mathrm{t}_{\mathrm{f}}}{\mathrm{h} \tan \psi} \ln \left[1+\left(\frac{\mathrm{h} \tan \psi}{\mathrm{t}_{\mathrm{f}}}\right)^{2}-\frac{\left(\frac{\mathrm{h} \tan \psi}{\mathrm{t}_{\mathrm{f}}}\right)}{1+\left(\frac{\mathrm{htan} \psi}{\mathrm{t}_{\mathrm{f}}}\right)^{2}}\right]\right\} .
\end{aligned}
$$

In this case, $\Psi=70.3^{\circ}$ and represents the half-angle of the tip conical indenter at the maximum load and $v$ is the Poisson ratio. In this case, as observed from Eq. (5b), the weight function does not depend on any adjustable parameter.

On the other hand, Bec et al. [23] developed an alternative formulation based on the consideration that the coating and substrate behave as two springs in series. In this case, the effective contact compliance was computed in terms of the contact radius, "a", by means of simple correcting parametric relationships of the form $\mathrm{f}(\mathrm{a})=1+\mathrm{k}_{\mathrm{B}} \mathrm{a}^{\mathrm{n}_{\mathrm{B}}}$, where $\mathrm{k}_{\mathrm{B}}$ and $\mathrm{n}_{\mathrm{B}}$ are constants. According to these authors the composite elastic modulus would be described by means of a harmonic law of mixtures of the form:

$\frac{1}{E_{C}}=\frac{\mathrm{a}_{\text {Bec }}\left(\mathrm{t}_{\mathrm{f}}, \mathrm{a}, \mathrm{h}\right)}{\mathrm{E}_{\mathrm{F}}}+\frac{1-\mathrm{a}_{\mathrm{Bec}}\left(\mathrm{t}_{\mathrm{f}}, \mathrm{a}, \mathrm{h}\right)}{\mathrm{E}_{\mathrm{S}}}$

where the corresponding weight function, $\mathrm{a}_{\mathrm{Bec}}\left(\mathrm{t}_{\mathrm{f}}, \mathrm{a}, \mathrm{h}\right)$, which does not require any empirical parameter, would be given by:

$\mathrm{a}_{\text {Bec }}\left(\mathrm{t}_{\mathrm{f}}, \mathrm{a}, \mathrm{h}\right)=\frac{2 \mathrm{t}_{\mathrm{f}}}{\pi \mathrm{a}\left(1+\frac{2 \mathrm{t}_{\mathrm{f}}}{\pi \mathrm{a}}\right)}=\frac{2 \mathrm{t}_{\mathrm{f}}}{\pi \mathrm{h} \tan \psi\left(1+\frac{2 \mathrm{t}_{\mathrm{f}}}{\pi \mathrm{tan} \psi}\right)}$.

Menčík and co-workers [18] also investigated the application of five different weight functions for determining the elastic modulus of thin homogeneous films from indentation measurements. The investigated functions involved different types, including a linear, exponential and reciprocal exponential, as well as the weight functions earlier put forward by Gao [17] and the Doerner and Nix [22]. Although these authors concluded that, in general, the indentation response of the different film/substrate systems investigated could be described by the Gao's analytical function, they also proposed the determination of the elastic modulus of thin films by means of an exponential weight function, used jointly either with a linear or a harmonic law of mixtures. Therefore, according to their first model, the composite elastic modulus would be given by:

$\mathrm{E}_{\mathrm{C}}=\mathrm{a}_{\mathrm{M} 1}\left(\alpha_{\mathrm{M} 1}, \mathrm{t}_{\mathrm{f}} / \mathrm{h}\right) \mathrm{E}_{\mathrm{F}}+\left(1-\mathrm{a}_{\mathrm{M} 1}\left(\alpha_{\mathrm{M} 1}, \mathrm{t}_{\mathrm{f}} / \mathrm{h}\right)\right) \mathrm{E}_{\mathrm{S}}$

where the corresponding weight function, $\mathrm{a}_{\mathrm{M} 1}\left(\alpha_{\mathrm{M} 1}, \mathrm{t}_{\mathrm{f}} / \mathrm{h}\right)$, would be expressed as:

$\mathrm{a}_{\mathrm{M} 1}\left(\alpha_{\mathrm{M} 1}, \mathrm{t}_{\mathrm{f}} / \mathrm{h}\right)=\exp \left[-\alpha_{\mathrm{M} 1} \frac{\mathrm{h}}{\mathrm{t}_{\mathrm{f}}}\right]$.

Also, according to their second model:

$\frac{1}{\mathrm{E}_{\mathrm{C}}}=\frac{\mathrm{a}_{\mathrm{M} 2}\left(\alpha_{\mathrm{M} 2}, \mathrm{t}_{\mathrm{f}} / \mathrm{h}\right)}{\mathrm{E}_{\mathrm{F}}}+\frac{1-\mathrm{a}\left(\alpha_{\mathrm{M} 2}, \mathrm{t}_{\mathrm{f}} / \mathrm{h}\right)}{\mathrm{E}_{\mathrm{S}}}$

where, again the corresponding weight function, $\mathrm{a}_{\mathrm{M} 2}\left(\alpha_{\mathrm{M} 2}, \mathrm{t}_{\mathrm{f}} / \mathrm{h}\right)$, would be given by:

$\mathrm{a}_{\mathrm{M} 2}\left(\alpha_{\mathrm{M} 2}, \mathrm{t}_{\mathrm{f}} / \mathrm{h}\right)=\exp \left[-\alpha_{\mathrm{M} 2} \frac{\mathrm{h}}{\mathrm{t}_{\mathrm{f}}}\right]$

Perriot and Barthel [19], by analyzing the contact problem of coated elastic materials, were able to develop a numerical algorithm based on an exact integral formulation of the elastic contact of an axisymmetric indenter onto a coated substrate. As part of their formulation, these authors proposed an empirical function for the description of the composited elastic modulus of the coated system, of the form:

$\mathrm{E}_{\mathrm{C}}=\left[1-\mathrm{a}_{\mathrm{PB}}\left(\beta_{\mathrm{PB}}, \mathrm{n}_{\mathrm{PB}}, \mathrm{t}_{\mathrm{f}} / \mathrm{h}\right)\right] \mathrm{E}_{\mathrm{F}}+\mathrm{a}_{\mathrm{PB}}\left(\beta_{\mathrm{PB}}, \mathrm{n}_{\mathrm{PB}}, \mathrm{t}_{\mathrm{f}} / \mathrm{h}\right) \mathrm{E}_{\mathrm{S}}$

where the corresponding weight function, $\mathrm{a}_{\mathrm{PB}}\left(\beta_{\mathrm{PB}}, \mathrm{n}_{\mathrm{PB}}, \mathrm{t}_{\mathrm{f}} / \mathrm{h}\right)$, would be 
given by:

$\mathrm{a}_{\mathrm{PB}}\left(\beta_{\mathrm{PB}}, \mathrm{n}_{\mathrm{PB}}, \mathrm{t}_{\mathrm{f}} / \mathrm{h}\right)=\frac{1}{1+\left(\frac{\beta_{\mathrm{PB}} \mathrm{t}_{\mathrm{f}}}{\mathrm{h} \tan \psi}\right)^{\mathrm{n}_{\mathrm{PB}}}}$.

In the above expression, both $\beta_{\mathrm{PB}}$ and $\mathrm{n}_{\mathrm{PB}}$ represent adjustable parameters.

Antunes et al. [20] also examined the influence of the elastic and plastic properties of both the substrate and film materials, which encompass a coated system, on the composite elastic modulus of the latter, by means of three-dimensional numerical simulations of the Vickers hardness test. In order to describe the change in the composite modulus as a function of the elastic modulus of film and substrate, these authors proposed two different formulations. The first one corresponds to a linear law of mixtures of the form:

$\mathrm{E}_{\mathrm{C}}=\left[1-\mathrm{a}_{\mathrm{A} 1}\left(\alpha_{\mathrm{A} 1}, \mathrm{t}_{\mathrm{f}} / \mathrm{h}\right)\right] \mathrm{E}_{\mathrm{F}}+\mathrm{a}_{\mathrm{A} 1}\left(\alpha_{\mathrm{A} 1}, \mathrm{t}_{\mathrm{f}} / \mathrm{h}\right) \mathrm{E}_{\mathrm{S}}$

where the weight function is expressed as:

$a_{A 1}\left(\alpha_{A 1}, t_{f} / h\right)=\exp \left(-\alpha_{A 1} \frac{t_{f}}{h}\right)$.

In the above expression, $\alpha_{\mathrm{A} 1}$ represents an adjustable parameter.

The second formulation advanced by Antunes and co-workers [20] corresponds to a harmonic law of mixtures, which involves the weight function proposed earlier by Gao et al. [17]:

$\frac{1}{\mathrm{E}_{\mathrm{C}}}=\frac{\mathrm{a}_{\mathrm{A} 2}\left(\mathrm{t}_{\mathrm{f}} / \mathrm{h}\right)}{\mathrm{E}_{\mathrm{F}}}+\frac{1-\mathrm{a}_{\mathrm{A} 2}\left(\mathrm{t}_{\mathrm{f}} / \mathrm{h}\right)}{\mathrm{E}_{\mathrm{S}}}$

where:

$\mathrm{a}_{\mathrm{A} 2}\left(\mathrm{t}_{\mathrm{f}} / \mathrm{h}\right)=\phi\left(\mathrm{h}, \mathrm{t}_{\mathrm{f}}, v\right)$.

Korsunsky and Constantinescu [21], in a subsequent investigation, analyzed the influence of punch tip sharpness on the interpretation of indentation measurements. This study involved the development of closed form solutions for the indentation of a homogeneous elastic half-space by an axisymmetric indenter of arbitrary shapes, which included Hertzian, conical, and conical with a rounded tip. In order to present the numerical results for the apparent contact modulus for elastic coated systems, as well as representing the apparent contact modulus as a function of the indentation depth, these authors proposed a formulation of the composite elastic modulus of the form:

$\mathrm{E}_{\mathrm{C}}=\mathrm{a}_{\mathrm{KC}}\left(\beta_{\mathrm{KC}}, \mathrm{n}_{\mathrm{KC}}, \mathrm{t}_{\mathrm{f}} / \mathrm{h}\right) \mathrm{E}_{\mathrm{F}}+\left[1-\mathrm{a}_{\mathrm{KC}}\left(\beta_{\mathrm{KC}}, \mathrm{n}_{\mathrm{KC}}, \mathrm{t}_{\mathrm{f}} / \mathrm{h}\right)\right] \mathrm{E}_{\mathrm{S}}$

where the corresponding weight function $\mathrm{a}_{\mathrm{KC}}\left(\beta_{\mathrm{KC}}, \mathrm{n}_{\mathrm{KC}}, \mathrm{t}_{\mathrm{f}} / \mathrm{h}\right)$ is similar to that employed for the description of the composite hardness of a coated system, as earlier proposed by Korsunsky and co-workers [33], which is given by:

$\mathrm{a}_{\mathrm{KC}}\left(\beta_{\mathrm{KC}}, \mathrm{n}_{\mathrm{KC}}, \mathrm{t}_{\mathrm{f}} / \mathrm{h}\right)=\frac{1}{1+\left(\frac{\mathrm{h}}{\beta_{\mathrm{KC}} \mathrm{t}_{\mathrm{f}}}\right)}$.

In the above expression, $\beta_{K C}$ and $n_{K C}$ represent adjustable parameters.

More recently, Bull $[23,24]$ has developed a simple formulation, which can be applied to both monolayer and multilayer coatings, which does not involve any adjustable parameter. As in the previous models, the composite modulus is expressed in terms of the coating and substrate moduli by means of a weight function, which is developed from the assumption that the indentation load is supported by a conical region of elastic deformation below the contact. Thus, by assuming that the substrate is very much thicker than the coating $\left(t_{s} \gg t_{f}\right)$ the composite modulus would be given by:

$\frac{1}{\mathrm{E}_{\mathrm{C}}}=\frac{1-\mathrm{a}_{\mathrm{B}}\left(\mathrm{t}_{\mathrm{f}} / \mathrm{h}\right)}{\mathrm{E}_{\mathrm{F}}}+\frac{\mathrm{a}_{\mathrm{B}}\left(\mathrm{t}_{\mathrm{f}} / \mathrm{h}\right)}{\mathrm{E}_{\mathrm{S}}}$

where the weighting function is expressed as:

$\mathrm{a}_{\mathrm{B}}\left(\mathrm{h}, \mathrm{t}_{\mathrm{f}}\right)=\frac{\pi \mathrm{a}_{0}}{\pi \mathrm{a}_{0}+2 \mathrm{t}_{\mathrm{f}}} \cong \frac{\pi \mathrm{h} \tan (\psi)}{\pi \mathrm{h} \tan (\psi)+2 \mathrm{t}_{\mathrm{f}}}$.

In the next section, the extension of all the preceding models to describe the composite elastic modulus of systems involving multilayer coatings, as well as determining the elastic modulus of each of the layers will be presented.

\section{Basis of the model}

According to the model proposed by Jönsson and Hogmark [34] for the analysis of monolayer coated systems under indentation, the composite hardness, $\mathrm{H}_{\mathrm{C}}$, can be expressed as a function of film and substrate hardness $\left(\mathrm{H}_{\mathrm{F}}\right.$ and $\mathrm{H}_{\mathrm{S}}$, respectively), by means of a simple law of mixtures of the form:

$\mathrm{H}_{\mathrm{C}}=\mathrm{b}\left(\mathrm{C}, \mathrm{t}_{\mathrm{f}}, \mathrm{h}\right) \mathrm{H}_{\mathrm{F}}+\left[1-\mathrm{b}\left(\mathrm{C}, \mathrm{t}_{\mathrm{f}}, \mathrm{h}\right)\right] \mathrm{H}_{\mathrm{S}}$

In the above equation, $\mathrm{b}\left(\mathrm{C}, \mathrm{t}_{\mathrm{f}}, \mathrm{h}\right)$ represents a weight function similar to that present in Eqs. (1a) and (1b) which is given by:

$\mathrm{b}\left(\mathrm{C}, \mathrm{t}_{\mathrm{f}}, \mathrm{h}\right)=2 \frac{\mathrm{Ct}_{\mathrm{f}}}{\mathrm{h}}-\frac{\mathrm{C}^{2} \mathrm{t}_{\mathrm{f}}^{2}}{\mathrm{~h}^{2}}=1-\left(1-\frac{\mathrm{Ct}_{\mathrm{f}}}{\mathrm{h}}\right)^{2}$.

In this case, such a function depends not only on the coating thickness and indentation depth, but also on a constant $\mathrm{C}$, which depends on the indentation behavior of the coating material (fracture or plastic deformation) and indenter geometry [32]. Thus, the product $\mathrm{Ct}_{\mathrm{f}}$ will determine the indentation depth at which the substrate will start to contribute to the composite hardness. Given the ill-definition of $b\left(c, t_{f}, h\right)$ as observed from equation (15), the weight function can be re-defined simply as follows:

$\begin{array}{ll}\mathrm{b}\left(\mathrm{C}, \mathrm{t}_{\mathrm{f}}, \mathrm{h}\right)=1 & \text { if } \quad \mathrm{h}<\mathrm{Ct}_{\mathrm{f}} \\ \mathrm{b}\left(\mathrm{C}, \mathrm{t}_{\mathrm{f}}, \mathrm{h}\right)=1-\left(1-\frac{\mathrm{Ct}_{\mathrm{f}}}{\mathrm{h}}\right)^{2} & \text { otherwise. }\end{array}$

Thus, according to Eq. (16), if $\mathrm{h}<\mathrm{Ct}_{\mathrm{f}}$, the composite hardness will be determined entirely by the coating, whereas in the opposite case, it will be determined by both coating and substrate. For a Berkovich indenter the product $\mathrm{Ct}_{\mathrm{f}}$ will vary between approximately $9-17 \%$ of the coating thickness [32].

The extension of this model to deal with multilayer coatings, conducted by Iost et al. [32], allowed the demonstration that the effective volume fraction of jth-layer of the multilayer coating, which contributes to the composite hardness, can be determined on the basis of Eq. (14) by taking into consideration the different layers involved in the indentation process. Thus, for the first layer of the coating:

$\mathrm{x}_{\mathrm{v}}{ }^{(1)}=1 \quad$ if $\quad \mathrm{h}<\mathrm{C}^{(1)} \mathrm{t}_{\mathrm{f}}{ }^{(1)}$

$\mathrm{x}_{\mathrm{v}}^{(1)}=\mathrm{b}^{(1)}=\left\{1-\left[1-\frac{\mathrm{C}^{(1)} \mathrm{t}_{\mathrm{f}}^{(1)}}{\mathrm{h}}\right]^{2}\right\}$ Otherwise. 
Therefore, the volume fraction for any given layer would be given by an expression of the form:

$\mathrm{x}_{\mathrm{v}}{ }^{(\mathrm{j})}=1-\sum_{\mathrm{i}=1}^{\mathrm{j}-1} \mathrm{x}_{\mathrm{v}}{ }^{(\mathrm{i})} \quad$ if $\quad \mathrm{h}<\sum_{\mathrm{i}=1}^{\mathrm{j}} \mathrm{C}^{(\mathrm{i})} \mathrm{t}_{\mathrm{f}}{ }^{(\mathrm{i})}$.

Otherwise:

$\mathrm{x}_{\mathrm{v}}^{(\mathrm{j})}=\mathrm{b}^{(\mathrm{j})}-\mathrm{b}^{(\mathrm{j}-1)}=\left\{1-\left[1-\frac{\sum_{\mathrm{i}=1}^{\mathrm{j}} \mathrm{c}^{(\mathrm{i})} \mathrm{t}_{\mathrm{f}}{ }^{(\mathrm{i})}}{\mathrm{h}}\right]^{2}\right\}-\left\{1-\left[1-\frac{\sum_{\mathrm{i}=1}^{\mathrm{j}-1} \mathrm{c}^{(\mathrm{i})} \mathrm{t}_{\mathrm{f}}^{(\mathrm{i})}}{\mathrm{h}}\right]^{2}\right\}$

That is to say:

$\mathrm{x}_{\mathrm{v}}^{(\mathrm{j})}=\left\{1-\left[1-\frac{\sum_{\mathrm{i}=1}^{\mathrm{j}} \mathrm{C}^{(\mathrm{i})} \mathrm{t}_{\mathrm{f}}{ }^{(\mathrm{i})}}{\mathrm{h}}\right]^{2}\right\}-\sum_{\mathrm{i}=1}^{\mathrm{j}-1} \mathrm{x}_{\mathrm{v}}{ }^{(\mathrm{i})}$

Thus, in principle, the effective volume fraction, which determines the contribution of any particular layer within the multilayer coating to the composite mechanical property, could be computed from the corresponding weight function associated to the specific model employed.

In the case of the characterization of the elastic modulus of coated systems involving monolayer coatings, a particular consideration that should be taken into account is the widely accepted notion that the interference of the substrate will occur when the indentation depth is greater than approximately $1 \%$ of the coating thickness [35-37], which is equivalent to setting $C=1 / 100$ for all the computations involved. In the analysis of coated systems which involve multilayer coatings, the interference of the $(j+1)$ layer or the substrate would then occur when the indentation depth is greater than approximately $1 \%$ of the summation of the $\mathrm{j}$ previous layers thickness, as illustrated below.

Regarding the different models mentioned above for the description of the change in the elastic modulus with penetration depth and taking, as an example, the model proposed by Doerner and Nix [22], according to the above formulation, the extension of this model to the analysis of the elastic properties of multilayer coatings, as well as its computational instrumentation, would require that for first layer:

$\mathrm{x}_{\mathrm{v}}{ }^{(1)}=1$ if $\mathrm{h}<\frac{\mathrm{t}_{\mathrm{f}}^{(1)}}{100}$.

Otherwise:

$\mathrm{x}_{\mathrm{v}}^{(1)}=1-\mathrm{a}_{\mathrm{DN}}{ }^{(1)}=\left\{1-\exp \left(-\alpha_{\mathrm{DN}}^{(1)} \frac{\mathrm{t}_{\mathrm{f}}^{(1)}}{\mathrm{h}-\frac{\mathrm{t}_{\mathrm{f}}^{(1)}}{100}}\right)\right\}$.

For the subsequent layers of the coating:

$\mathrm{x}_{\mathrm{v}}{ }^{(\mathrm{j})}=1-\sum_{\mathrm{i}=1}^{\mathrm{j}-1} \mathrm{x}_{\mathrm{v}}{ }^{(\mathrm{i})} \quad$ if $\quad \mathrm{h}<\frac{1}{100} \sum_{\mathrm{i}=1}^{\mathrm{j}} \mathrm{t}_{\mathrm{f}}{ }^{(\mathrm{i})}$.
Otherwise:

$$
\begin{aligned}
& \mathrm{x}_{\mathrm{v}}{ }^{(\mathrm{j})}=\left[1-\mathrm{a}_{\mathrm{DN}}{ }^{(\mathrm{j})}\right]-\left[1-\mathrm{a}_{\mathrm{DN}}{ }^{(\mathrm{j}-1)}\right] \text { or } \\
& \mathrm{x}_{\mathrm{v}}{ }^{(\mathrm{j})}=\left\{1-\exp \left(-\alpha_{D N}{ }^{(\mathrm{j})} \frac{\sum_{\mathrm{i}=1}^{\mathrm{j}} \mathrm{t}_{\mathrm{f}}^{(\mathrm{i})}}{\mathrm{h}-\frac{1}{100} \sum_{\mathrm{i}=1}^{\mathrm{j}} \mathrm{t}_{\mathrm{f}}^{(i)}}\right)\right\}-\left\{1-\exp \left(-\alpha_{D N}{ }^{(\mathrm{j}-1)} \frac{\sum_{\mathrm{i}=1}^{\mathrm{j}-1} \mathrm{t}_{\mathrm{f}}{ }^{(i)}}{\mathrm{h}-\frac{1}{100} \sum_{\mathrm{i}=1}^{\mathrm{j}-1} \mathrm{t}_{\mathrm{f}}{ }^{(\mathrm{i})}}\right)\right\}
\end{aligned}
$$

After the computation of the volume fraction of each layer, the corresponding volume fraction of the substrate material is determined by means of:

$\mathrm{X}_{\mathrm{v}}{ }^{(\mathrm{S})}=1-\sum_{\mathrm{i}=1}^{\mathrm{N}} \mathrm{x}_{\mathrm{v}}{ }^{(\mathrm{i})}$.

$\mathrm{N}$ represents the number of layers of the multilayer coating.

Thus, according to this model, the composite elastic modulus of the multilayer coating can be calculated from the following relationship:

$\frac{1}{E_{C}}=\sum_{i=1}^{N} \frac{x_{\mathrm{v}}{ }^{(i)}}{E_{F}^{(i)}}+\frac{x_{V}{ }^{(S)}}{E_{S}}$.

Thus, the modified version of the Doerner and Nix model, in order to analyze multilayer coatings, would require the determination of $(2 \mathrm{~N}+1)$ parameters. This computation is carried out by means of non-linear regression analysis of the experimental data available, as shown in the forthcoming.

Finally, Eqs. (19a), (20a) and (21) will be the same for any other model chosen to represent the change in the composite elastic modulus with penetration depth data. Appendix 1 summarizes the corresponding formulation and computational instrumentation for the models advanced by Gao et al. [17], Bec et al. [23], Menčík et al. [18], Perriot and Barthel [19], Antunes et al. [20], Korsunsky and Constantinescu [21] and Bull [24,25].

\section{Experimental materials and techniques}

In order to validate the modified form of the different models indicated above, the nanoindentation data obtained from a multilayer coating deposited onto a 2024-T6 aluminum alloy was employed. However, in order to improve the load-carrying capacity, the aluminum alloy substrate was coated with a NiP plating of approximately $52 \mu \mathrm{m}$ in thickness, prior to the PVD deposition of a hydrogenated a-C:H diamondlike carbon (DLC) film, commercially known as Dymon-iC ${ }^{\mathrm{TM}}$. Therefore the NiP plating acted as an intermediate layer between the DLC film and the aluminum substrate. PVD deposition was carried out at Teer Coatings, U.K. Deposition was conducted by means of closed field unbalanced magnetron sputtering ion platting (CFUBMSIP), coupled with plasma assisted chemical vapor deposition (PACVD). Details of the deposition techniques and characterization of the coated system have been reported elsewhere [38,39]. As reported by Staia et al. [39], the coating roughness was of $0.2 \pm 0.01 \mu \mathrm{m}$ prior to DLC deposition.

Nanoindentation tests were carried out in order to obtain the loaddisplacement data by employing a Nanoindenter (MTS System Corporation, Oak Ridge, TN) equipped with a Berkovich diamond indenter tip, using a continuous contact stiffness measurement (CSM) mode. Such a mode provides continuous load and indentation depth measurements during loading by superimposing a $2 \mathrm{~nm}$ harmonic oscillation on the loading curve, at a frequency of $45 \mathrm{~Hz}$. Both elastic modulus and hardness data were continuously determined during loading up to the maximum load by means of the Oliver and Pharr (OP) method [40]. The maximum loads applied were in the range of $7000 \mathrm{mN}$. The diamond tip calibration was performed following the procedure of OP, by determining the Berkovich indenter area function, $A\left(h_{c}\right)$, evaluated at the 
contact depth, $\mathrm{h}_{\mathrm{c}}$. For this purpose, a fused silica sample supplied by the instrument manufacturer, whose elastic modulus is $72 \mathrm{GPa}$, was employed. As will be presented in the next section, the elastic modulus of this sample was found to be constant for penetration depths greater than approximately $8-10 \mathrm{~nm}$. Thus, the real contact depth, defined as $\mathrm{h}_{\mathrm{c}}=\mathrm{h}_{\max }-0.75 \mathrm{P} / \mathrm{S}$, was measured continuously. Here, $\mathrm{h}_{\max }$ represents the maximum penetration depth, $P$ the load and $S$ the contact stiffness, which is defined as the ratio of the load to depth amplitudes of the small harmonic oscillations.

Three different samples of the coated system were employed and on each specimen 25 indentations were conducted. A constant indentation rate of $0.05 \mathrm{~s}^{-1}$ was employed and both the hardness and elastic modulus versus penetration depth were recorded continuously up to approximately $7000 \mathrm{~nm}$. The Oliver and Pharr method [40] was used in order to analyze the results of the indentation tests, since this material was not observed to exhibit significant pile-up or sink-in phenomena.

A CrC intermediate layer was deposited onto the NiP plating prior to the deposition of the DLC coating, which in principle represents a multilayer coating consisting of DLC film and a $\mathrm{CrC}$ coating with a total thickness in the range of $2.2 \mu \mathrm{m}$, both deposited onto an electroless $\mathrm{NiP}$ plating of about $52 \mu \mathrm{m}$ in thickness. As indicated above, the trilayer coating was deposited onto an aluminum substrate. This coated system has been thoroughly characterized by Staia et al. [39] employing electron microprobe analysis (EMPA) techniques. These authors have reported that a diffusive reaction between the DLC, $\mathrm{CrC}$ and NiP took place during PVD deposition. Such a reaction occurred over a distance of approximately $4 \mu \mathrm{m}$ into the NiP from the $\mathrm{CrC}-\mathrm{NiP}$ interface. Thus, as a consequence of this diffusive reaction, a distinctive layer of $\mathrm{CNiPCr}$ was formed.

Therefore, in order to test the validity of the modified models employed for the description of the composite elastic modulus with penetration depth, the multilayer coating will be considered to exhibit the following architecture: a first layer of DLC, with a thickness of $900 \mathrm{~nm}$, a second layer of $\mathrm{CrC}$ with a thickness of $1200 \mathrm{~nm}$ and a diffusive layer of CNiPCr with a thickness of $4000 \mathrm{~nm}$. Given the thickness of the remaining electroless NiP plating, of approximately $48 \mu \mathrm{m}$, and the fact that, as shown in the forthcoming, the composite elastic modulus versus penetration depth, up to approximately $7000 \mathrm{~nm}$, does not show any influence of the aluminum alloy, the NiP plating will be considered as the "substrate" for all practical purposes.

\section{Experimental results}

Fig. 1 illustrates the response of the fused silica standard employed for the calibration of the indenter used in the nanoindentation tests. As can be clearly observed, from a penetration depth of about $7 \mathrm{~nm}$,

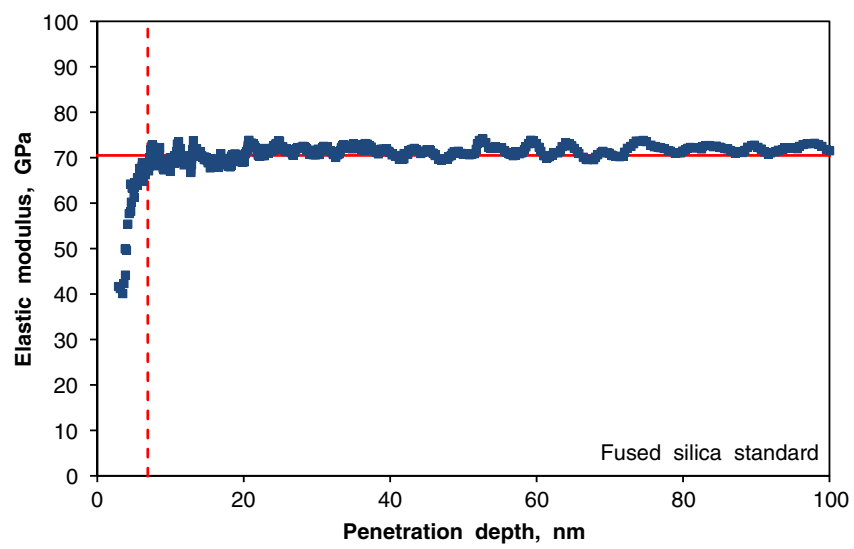

Fig. 1. Calibration curve for the Berkovich indenter employed in the present investigation, by means of a fused silica standard. A constant value of the elastic modulus of approximately $71 \mathrm{GPa}$ is obtained above $7 \mathrm{~nm}$ of penetration depth.

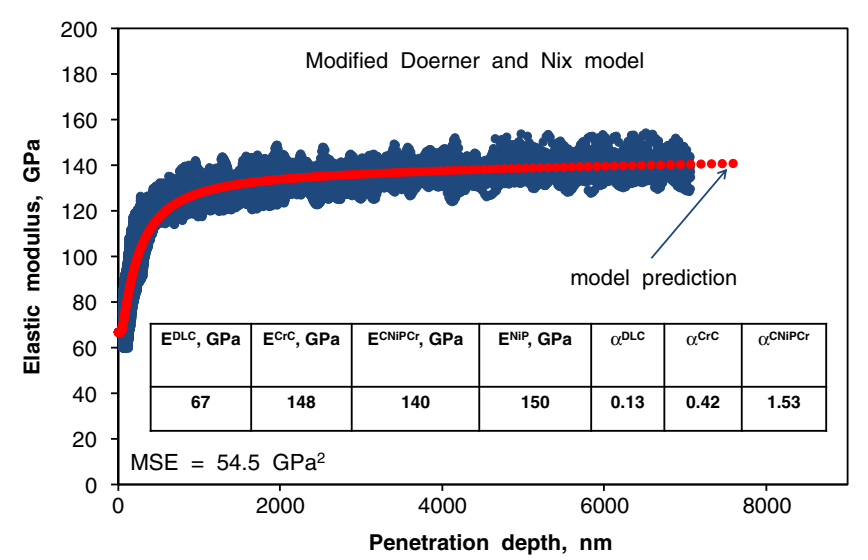

Fig. 2. Change in the experimental values of the composite elastic modulus as a function of penetration depth for the coated system under investigation. The description of the experimental data has been conducted with the modified Doerner and Nix model.

the elastic modulus of the material becomes constant at a value of approximately $71 \mathrm{GPa}$. However, as far describing the change in the composite elastic modulus with indentation depth and analyzing the behavior of each layer while avoiding any experimental artifact related to the elastic-plastic transition that occurs at low contact depths, only the experimental data concerning penetration depths higher than $50 \mathrm{~nm}$ were considered. Figure 2 includes approximately 20 thousand experimental points, which correspond to the individual $\mathrm{E}$ versus $\mathrm{h}$ curves obtained in each indentation test.

Thus, Figs. 2 through 19 illustrate the results obtained regarding the description of the change both in the composite elastic modulus and volume fraction of the layers contributing to the composite modulus, with penetration depth. As shown in Fig. 2, the experimental values of the composite elastic modulus exhibit a wide scatter band, starting from a magnitude of approximately $60 \mathrm{GPa}$ at $50 \mathrm{~nm}$. As the penetration depth, h, increases to values of approximately $500 \mathrm{~nm}$, the composite modulus also increases at a relatively high rate to a magnitude in the range of 113-133 GPa.

However, as h continues to increase and higher values are achieved, the composite modulus tends to attain a saturation value in the range of approximately $141 \pm 11 \mathrm{GPa}$. This magnitude is entirely consistent with that reported by Staia et al. [39], who conducted nanoindentation tests on the reverse side of the same DLC coated samples under investigation and reported a value of approximately $140 \pm 10 \mathrm{GPa}$ for the electroless NiP plating. Therefore, it is expected that any model employed for the description of these data will predict a relatively low value for the DLC

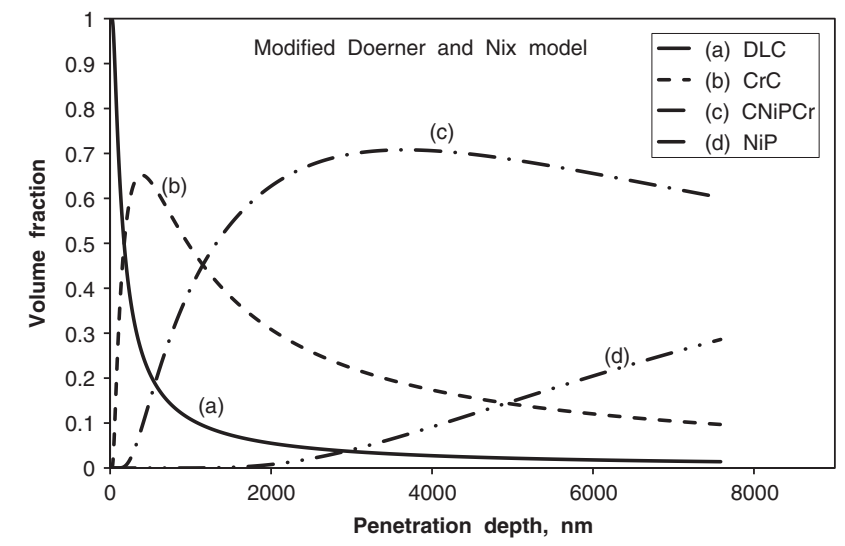

Fig. 3. Change in the volume fraction of each layer contributing to the composite elastic modulus, according to the modified Doerner and Nix model, as a function of penetration depth. 


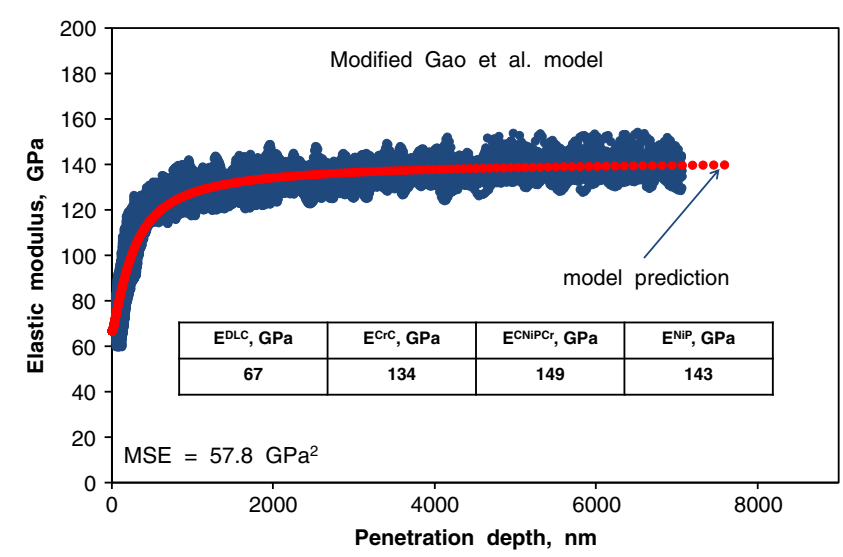

Fig. 4. Change in the experimental values of the composite elastic modulus as a function of penetration depth for the coated system under investigation. The description of the experimental data has been conducted with the modified Gao et al. model.

modulus, in the range between 60-70 GPa and a much greater magnitude for the $\mathrm{CrC}, \mathrm{CNiPCr}$ and NiP layers, in the range of approximately 90-150 GPa.

Fig. 2 also illustrates the prediction of the change in the composite elastic modulus provided by the model advanced by Doerner and Nix [22]. The values of the elastic modulus and the constant $\alpha_{\text {DN }}$ of each one of the layers, which compose the coating, are given on the plot. As can be observed from Fig. 2, the model provides a satisfactory description of the experimental data and according to Fig. 3, the elastic response of the multilayer coating is determined mainly by the DLC, $\mathrm{CrC}$ and $\mathrm{CNiPCr}$ layers. On the contrary, the effect of the NiP plating considered as the substrate becomes important at penetration depths greater than about $2000 \mathrm{~nm}$, although its contribution to the composite modulus at the end of the indentation process is less than approximately $30 \%$. Fig. 2 also illustrates the value of the Mean Square Error (MSE), defined as:

$$
\text { MSE }=\frac{\sum_{\mathrm{i}=1}^{\mathrm{N}_{\text {exp. }}}\left[\left(\mathrm{E}_{\mathrm{C} \text { Exp. }}\right)_{\mathrm{i}}-\left(\mathrm{E}_{\mathrm{CCal}}\right)_{\mathrm{i}}\right]^{2}}{\mathrm{~N}_{\text {exp. }}-\mathrm{N}_{\mathrm{Par}}} .
$$

Where, $\mathrm{N}_{\text {Par }}$ represents the number of adjustable parameters that intervene in the model, $\mathrm{N}_{\text {exp. }}$ the number of experimental data points, $\mathrm{E}_{\mathrm{C}}$ Exp. the experimental values of the composite elastic modulus and $\mathrm{E}_{\mathrm{C}}$ cal. the module values computed with the model employed. In this

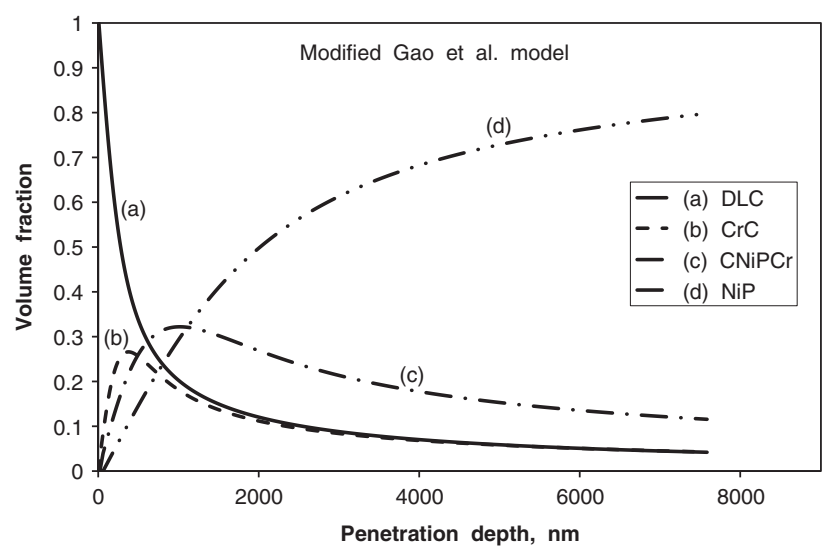

Fig. 5. Change in the volume fraction of each layer contributing to the composite elastic modulus, according to the modified Gao et al. model, as a function of penetration depth.

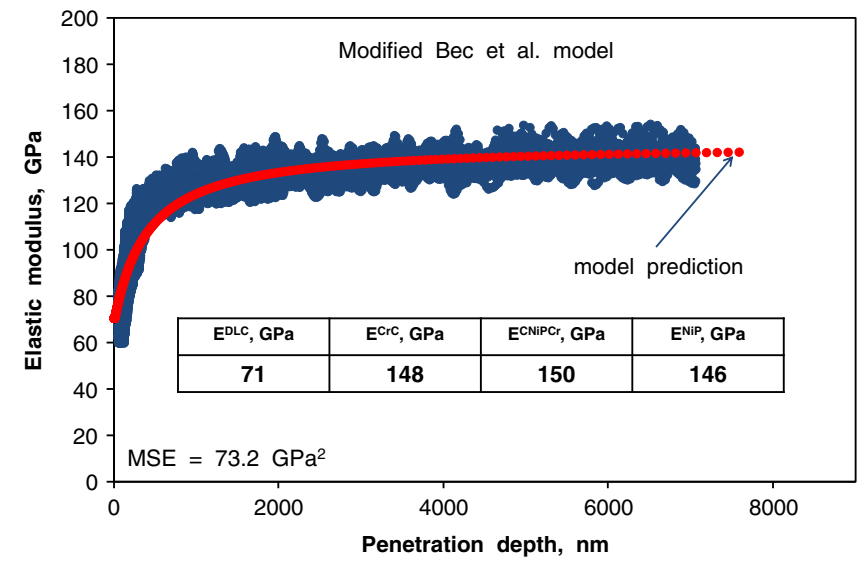

Fig. 6. Change in the experimental values of the composite elastic modulus as a function of penetration depth for the coated system under investigation. The description of the experimental data has been conducted with the modified Bec et al. model.

way, it would be possible to conduct a crude ranking of the different models that have been tested. For the present model, MSE $=54.5 \mathrm{GPa}^{2}$.

The model advanced by Gao et al. [17] does not involve any material parameter, other than the corresponding values of the elastic modulus of each layer, as well as that of the substrate. However, as indicated in Appendix 1, the model requires some knowledge of the Poisson ratio of the materials, which constitute the different layers of the multilayer coating. In the present case, it has been assumed that $v^{(\mathrm{DLC})}=0.30$ [41], $v^{(\mathrm{CrC})}=0.33$ [42], $v^{(\mathrm{CNiPCr})}=0.31[43]$ and $v^{(\mathrm{NiP})}=0.30$ [44]. The results corresponding to this model are presented in Figs. 4 and 5. As can be observed in Fig. 4, the description of the experimental data provided by this model is also very satisfactory $\left(\mathrm{MSE}=57.8 \mathrm{GPa}^{2}\right)$. Contrary to the previous model, as shown in Fig. 5, this approach predicts the intervention of the NiP plating at a much earlier stage, which becomes dominant at penetration depths in the range of approximately $1120 \mathrm{~nm}$. As the penetration depth increases from this value, the composite modulus is determined by the NiP and $\mathrm{CNiPCr}$ layers, since the influence of the DLC and $\mathrm{CrC}$ layers becomes relatively small.

The model proposed by Bec et al. [23] has similar characteristics to those of the model advanced by Gao et al. [17], in the sense that no additional material parameters are involved. As shown in Fig. 6, the description of the experimental data is also satisfactory, particularly for penetration depths greater than approximately $1500 \mathrm{~nm}$, which results in a somewhat higher MSE. The evolution of the volume faction of each layer, presented in Fig. 7, is also quite similar to the predicted by the previous model, the most important difference being the stronger influence of the NiP substrate than in the previous case.

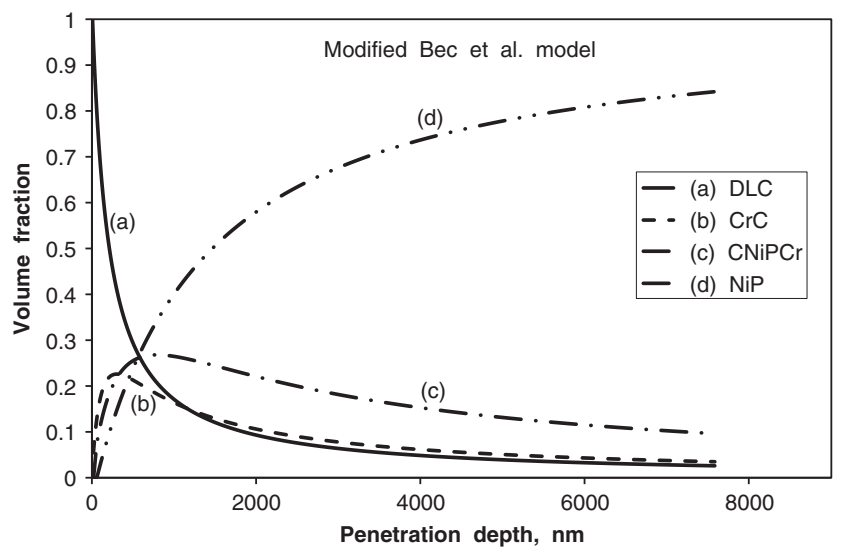

Fig. 7. Change in the volume fraction of each layer contributing to the composite elastic modulus, according to the modified Bec et al. model, as a function of penetration depth. 


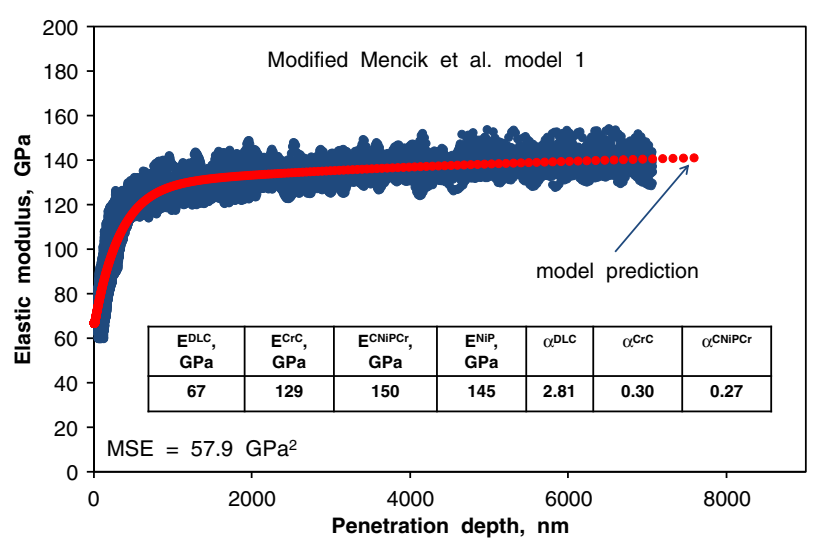

Fig. 8. Change in the experimental values of the composite elastic modulus as a function of penetration depth for the coated system under investigation. The description of the experimental data has been conducted with the modified Menčík et al. model 1.

The results corresponding to the first model advanced by Menčík et al. [18] are illustrated in Figs. 8 and 9. The number of parameters involved is similar to that of the Doerner and Nix model [22] and also the MSE is very similar. Therefore, the description provided by the model can also be considered as satisfactory. However, an important difference in comparison with the previous models is the predicted influence of the $\mathrm{CrC}$ layer and its evolution in the course of the indentation process. As shown in Fig. 9, the $\mathrm{CrC}$ film becomes the determining layer, regarding the elastic behavior of the coating, at penetration depths of approximately $250 \mathrm{~nm}$, extending its influence up to about $5000 \mathrm{~nm}$. At such a penetration depth, the elastic response of the coating is determined by the $\mathrm{CrC}$ and $\mathrm{CNiPCr}$ layers, as well as the NiP substrate.

Regarding the second model proposed by these authors [18], Figs. 10 and 11 illustrate the corresponding predictions. As shown in Fig. 10, the description of the experimental data provided by this model is significantly better than that of their first model $\left(\mathrm{MSE}=51.8 \mathrm{GPa}^{2}\right)$ and somewhat better than that provided by the Doerner and Nix model [22]. However, a particular characteristic of the predicted volume fraction evolution, shown in Fig. 11, is the negligible influence of the $\mathrm{CNiPCr}$ layer on the elastic response of the coating. Therefore, the elastic response is entirely determined by the DLC film, up to about $150 \mathrm{~nm}$ and the $\mathrm{CrC}$ layer up to approximately $4000 \mathrm{~nm}$. At higher penetration depths, the elastic response is mainly determined by the NiP substrate.

The model advanced by Perriot and Barthel [19] involves two additional material parameters, besides the elastic modulus, for each layer, which provides a satisfactory description of the experimental data, as illustrated in Fig. 12. Such an elastic response is determined by the DLC

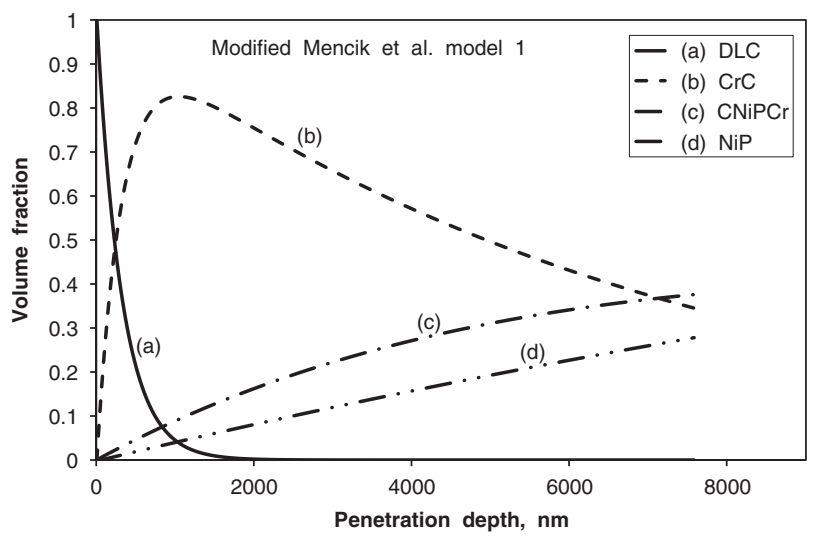

Fig. 9. Change in the volume fraction of each layer contributing to the composite elastic modulus, according to the modified Menčík et al. model 1, as a function of penetration depth.

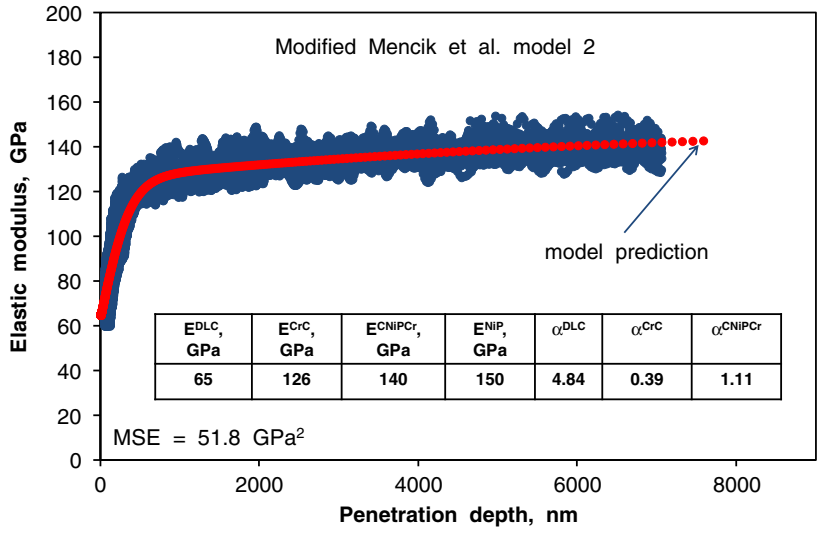

Fig. 10. Change in the experimental values of the composite elastic modulus as a function of penetration depth for the coated system under investigation. The description of the experimental data has been conducted with the modified Menčík et al. model 2.

film, up to about $230 \mathrm{~nm}$, the $\mathrm{CrC}$ layer, between 230 and $600 \mathrm{~nm}$ and the NiP substrate, which dominates at indentation depths higher than $600 \mathrm{~nm}$. An interesting aspect shown in Fig. 12 is that, according to this model, the $\mathrm{CrC}$ layer has a stronger influence on the elastic response of the coating than the diffusion $\mathrm{CNiPCr}$ layer with a thickness of approximately $4000 \mathrm{~nm}$. The model exhibits a MSE somewhat higher than that of the Doerner and Nix model in spite of the number of parameters involved.

The results concerning the first model advanced by Antunes et al. [20] are presented in Figs. 14 and 15. Fig. 14 illustrates that the model is able to describe quite satisfactorily the change in the experimental values of the composite modulus with penetration depth, which allows a MSE value close to that found for the second model proposed by Menčík et al. [18]. The evolution of the volume fraction for each layer, shown in Fig. 15, indicates that, according to this model, the elastic response of the multilayer coating is determined at first by the DLC film, up to an indentation depth of approximately $400 \mathrm{~nm}$, followed by the $\mathrm{CrC}$ layer, between approximately 400 and $700 \mathrm{~nm}$, until the $\mathrm{CNiPCr}$ layer becomes dominant, from $600 \mathrm{~nm}$ until the end of the indentation process. Substrate effects are first observed at approximately $1700 \mathrm{~nm}$, but never achieve more than $40 \%$.

The second model proposed by Antunes et al. [20] is based on the use of the function $\phi$ introduced by Gao et al. [17]. Therefore, the model does not include any additional material parameters besides the corresponding elastic modules. As can be observed in Fig. 16, the model provides a satisfactory description of the experimental data, particularly for penetration depths greater than approximately $1500 \mathrm{~nm}$. For

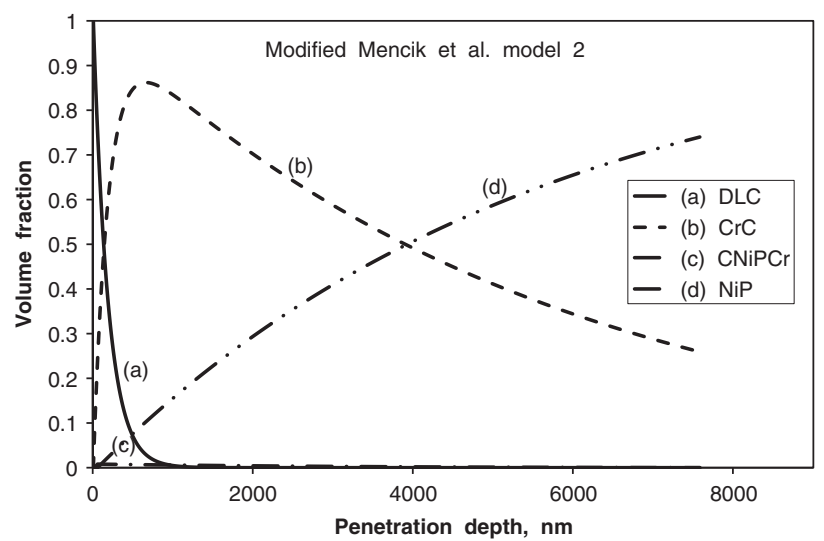

Fig. 11. Change in the volume fraction of each layer contributing to the composite elastic modulus, according to the modified Menčík et al. model 2, as a function of penetration depth. 


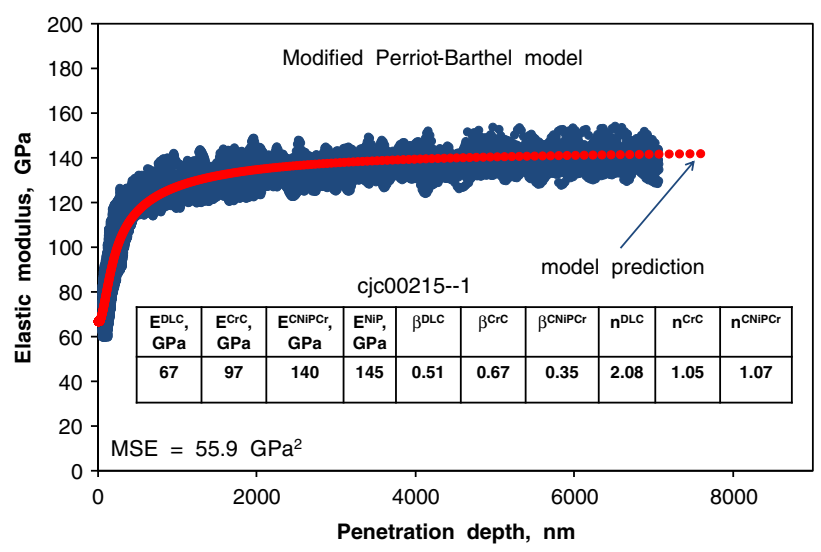

Fig. 12. Change in the experimental values of the composite elastic modulus as a function of penetration depth for the coated system under investigation. The description of the experimental data has been conducted with the modified Perriot-Barthel model.

penetration depths less than this value, the model tends to underestimate slightly the experimental values of the composite modulus, which increases the magnitude of the MSE to a similar level of that found for the Bec et al. model [23]. As expected, the evolution of the volume fraction of each coating layer, shown in Fig. 17, is very similar to that describe for the Gao et al. model [17], with predominance of the DLC layer up to approximately $600 \mathrm{~nm}$, followed by the CNiPCr layer up to $1100 \mathrm{~nm}$. Above this limit, the elastic response of the coating is determined by the NiP plating.

The model advanced by Korsunsky and Constantinescu [21] provides an excellent description of the experimental data, as shown in Fig. 18. However, this description is achieved at the expense of increasing the number of material parameters involved in the model. Similarly to the model advanced by Perriot and Barthel [19], this approach introduces two additional material parameters for each layer of the coating. The MSE corresponding to this model is the lowest of all the models analyzed, partially as a consequence of the number of parameters that are involved. The evolution of the volume fraction of each layer, as predicted by the model, indicates the dominant effect of the DLC film up to penetration depths of approximately $250 \mathrm{~nm}$, followed by the $\mathrm{CrC}$ layer up to about $2500 \mathrm{~nm}$, although the CNiPCr layer also exhibits an important contribution from approximately $500 \mathrm{~nm}$. Beyond penetration depths of 2500 the elastic response of the coating is mainly determined by the NiP substrate.

Finally, Figs. 20 and 21 illustrate the results predicted by the model of Bull $[24,25]$. This model does not involve any additional material parameters to the corresponding elastic modulus of the individual layers

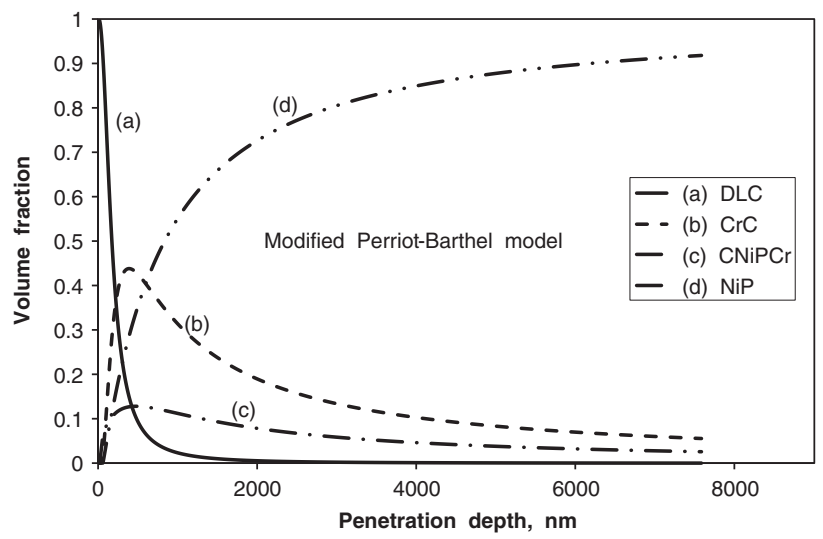

Fig. 13. Change in the volume fraction of each layer contributing to the composite elastic modulus, according to the modified Perriot-Barthel model, as a function of penetration depth.

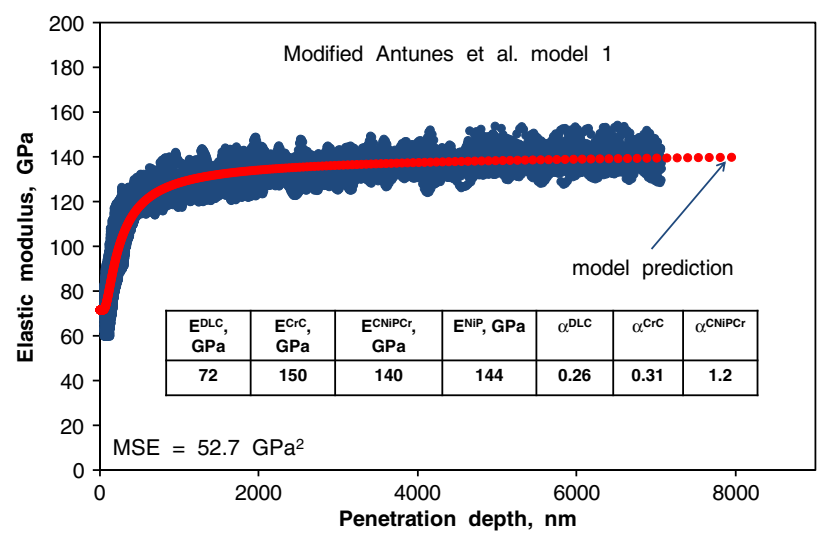

Fig. 14. Change in the experimental values of the composite elastic modulus as a function of penetration depth for the coated system under investigation. The description of the experimental data has been conducted with the modified Antunes et al. model 1.

and represent the only model, of those under study, which has been extended to the analysis of multilayer coatings. A comparison of the figures mentioned above with Figs. 6 and 7 shows clearly that the results obtained with this model are identical as those obtained with the model advanced by Bec at al. [23], in agreement with the findings of Bull [25]. Therefore, both formulations can be considered to be equivalent if the substrate thickness is assumed to be "infinite" in Bull's model.

According to the results that have been presented, predicted by the different modified models, the DLC film concerning the present investigation has a mean elastic modulus of approximately $69 \pm 3 \mathrm{GPa}$, whereas those corresponding to the $\mathrm{CrC}$ and $\mathrm{CNiPCr}$ layers are approximately $135 \pm 17 \mathrm{GPa}$ and $144 \pm 5 \mathrm{GPa}$, respectively. The mean elastic modulus of the NiP plating has been found to be approximately $146 \pm 2 \mathrm{GPa}$, in agreement with the results obtained from the tests conducted on the reverse side of the coated specimens.

\section{Discussion}

One of the crucial aspects of extending any model developed for the analysis of the elastic response of monolayer coatings to systems involving multilayer coatings under indentation loads is the definition of the volume fraction of the different layers and their corresponding contribution to the composite elastic modulus. This critical issue was satisfactorily solved by lost et al. [32], by taking into consideration the physical meaning related to the indentation area. Although it is not explicitly indicated in their original work, the results of such analysis show that the

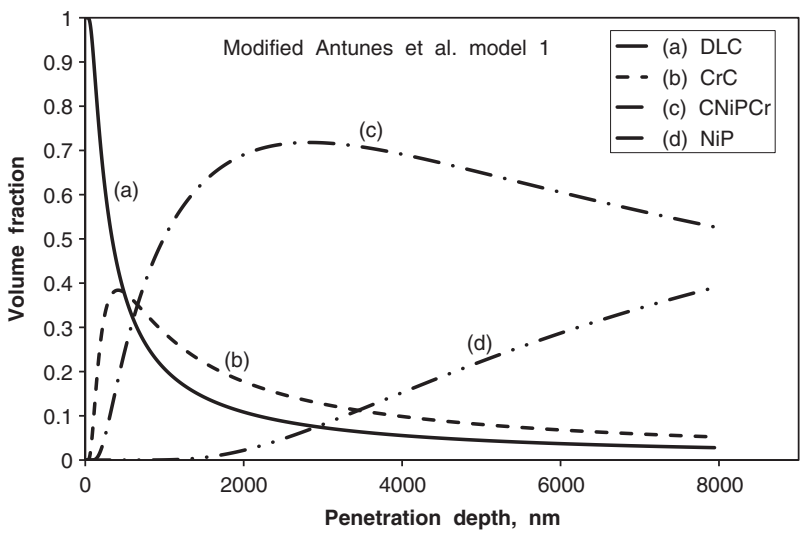

Fig. 15. Change in the volume fraction of each layer contributing to the composite elastic modulus, according to the modified Antunes et al. model 1, as a function of penetration depth. 


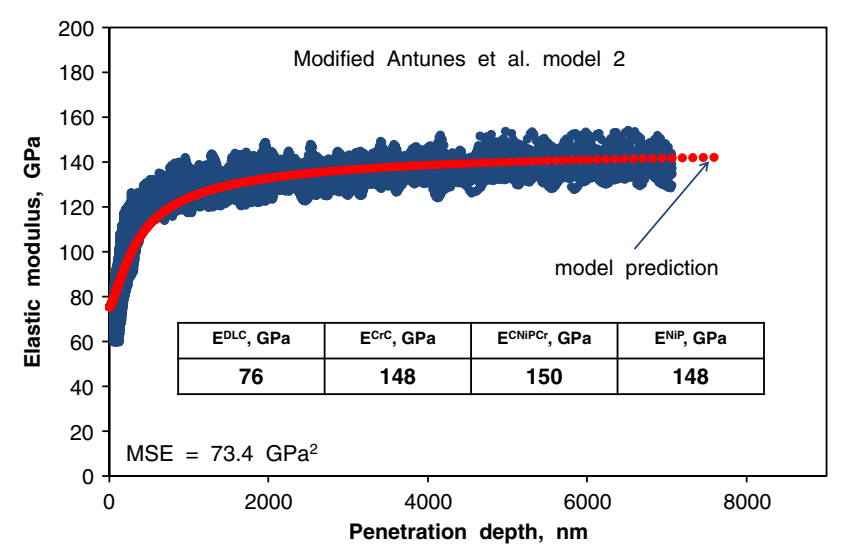

Fig. 16. Change in the experimental values of the composite elastic modulus as a function of penetration depth for the coated system under investigation. The description of the experimental data has been conducted with the modified Antunes et al. model 2.

volume fraction of each layer can be determined from the weight function employed either in the linear or harmonic law used for the description of the composite mechanical property measured as a function of the indentation depth.

This feature, expressed by Eqs. (17a), (17b), (18a), (18b) and (18c), allows a generalization of the physically-based concept advanced by Iost and co-workers [32]. Thus, once the volume fraction corresponding to the first layer is determined, the volume fraction of the subsequent layer can be easily computed from the corresponding weight function and by subtracting the prior volume fraction. The determination of the volume fraction of the remaining layers should follow a similar procedure by taking into account the thickness of the layers involved and the fractions of such thicknesses from which the layers below or substrate will start exerting their influence.

In the present case, the analysis has been based on the commonly accepted notion that the limiting penetration depth for the interference of the layers below that under examination or substrate is in the range of $1 \%$ [35-37]. Therefore, the fact that the volume fraction of a particular layer in the coating can be computed from the difference between the global volume fraction (determined by taking into account the current indentation depth and the thickness of the different layers involved) and the previously computed volume fractions for the upper layers, allows the general extension of this methodology to any model, other than that advanced by Jönsson and Hogmark [34], for which, the concept was first developed.

The results presented in Figs. 2 through 21 for the ten different models analyzed in the present work indicate that the use of this

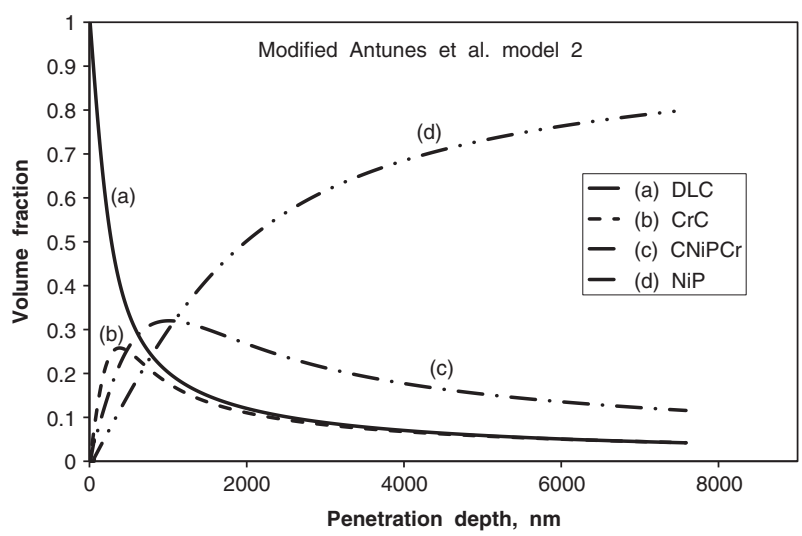

Fig. 17. Change in the volume fraction of each layer contributing to the composite elastic modulus, according to the modified Antunes et al. model 2, as a function of penetration depth.

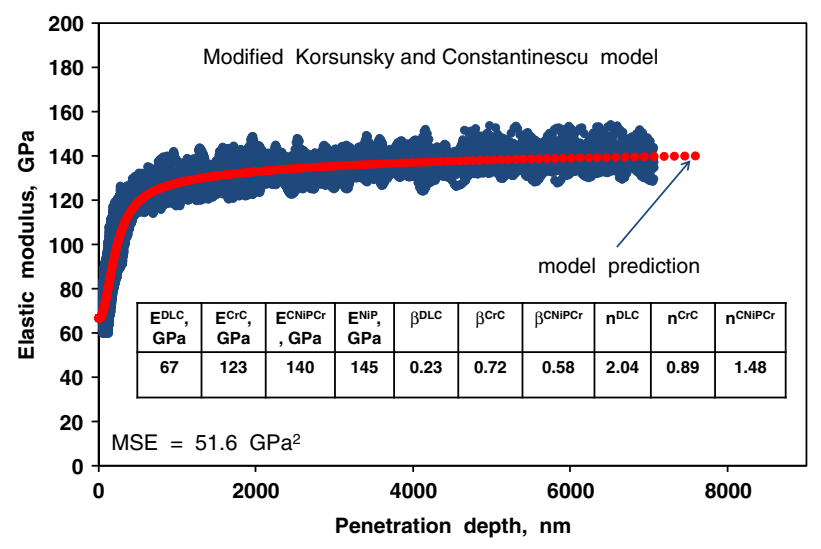

Fig. 18. Change in the experimental values of the composite elastic modulus as a function of penetration depth for the coated system under investigation. The description of the experimental data has been conducted with the modified Korsunsky and Constantinescu model.

concept provides quite satisfactory results regarding the description of the change in the composite elastic modulus with indentation depth, as well as the computation of the elastic modulus of each of the layers involved in the coating. As expected, the quality of such a description depends on the number of material parameters involved in the model, which also has a significant influence on the MSE of the computation.

The structure of each model and particularly the form of its weight function has also a significant effect on the prediction of the volume fraction evolution in the course of the indentation process. This feature can be clearly observed in Figs. 22 and 23, which illustrate the volume fraction evolution for the DLC, $\mathrm{CrC}$ and CNiPCr layers, as well as that of the NiP plating considered as substrate. As shown in Fig. 22a, the influence of the DLC film on the elastic response of the coating is quite similar in all the models, up to penetration depths in the range of approximately $300 \mathrm{~nm}$, which leads to the clustering of the different curves, hindering their distinction. Thus, as can be observed in Fig. 22b (where the maximum indentation depth has been limited to $2000 \mathrm{~nm}$ ) as penetration depth increases, the predicted evolution of this volume fraction varies according to each model. Some of the models (e.g., Gao et al., Bec et al., Antunes et al., Doerner and Nix and Bull) predict a stronger contribution of this layer than others (Menčík et al., Perriot-Barthel, Korsunsky and Constantinescu).

Regarding the influence of the $\mathrm{CrC}$ layer on the elastic response of the coating, as shown in Fig. 23a, the strongest influence is predicted by the two models advanced by Menčík et al., whereas the weakest influence is predicted by the models advanced by Gao et al., Bec et al. and

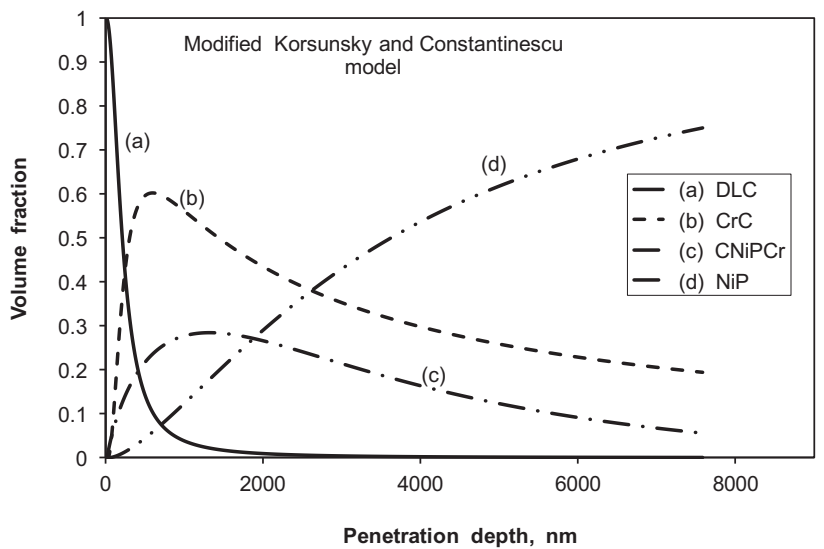

Fig. 19. Change in the volume fraction of each layer contributing to the composite elastic modulus, according to the modified Korsunsky and Constantinescu model, as a function of penetration depth. 


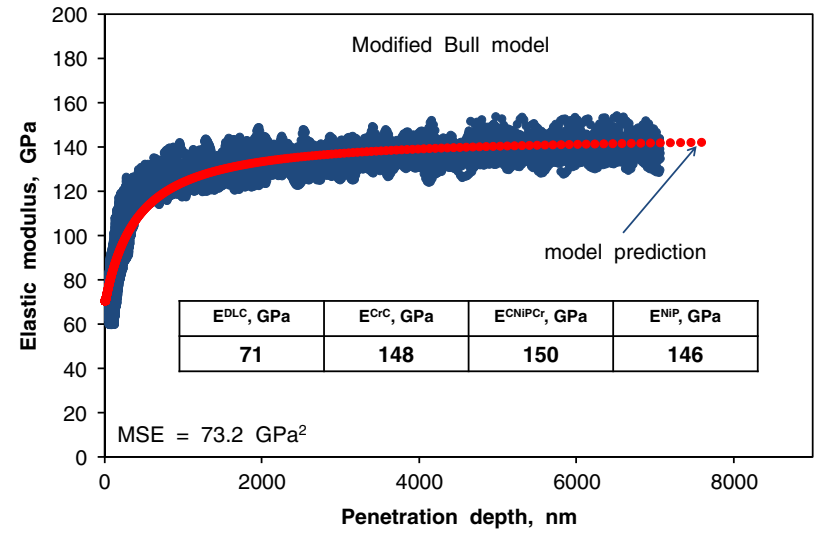

Fig. 20. Change in the experimental values of the composite elastic modulus as a function of penetration depth for the coated system under investigation. The description of the experimental data has been conducted with the modified Bull model.

Bull. The predictions of the other models are observed to range between these extremes. A similar spread is observed for the volume fraction evolution of the CNiPCr layer, which shows distinct features, as illustrated in Fig. 23b. In this case, the strongest influence is predicted by the models of Doerner and Nix and Antunes et al. (model 1).

In both cases, the volume fraction tends to decrease as the indentation depth increases beyond approximately $3500 \mathrm{~nm}$. Other models, such as those proposed by Gao et al., Bec et al., Perriot-Barthel, Korsunsky-Constantinescu and Bull predict a much weaker influence of this layer and also exhibit a trend to decrease with penetration depth from approximately $1000 \mathrm{~nm}$. The two exceptions to this general description are exhibited by the two models proposed by Menčík et al., one of which predicts a steady increase (model 1) and the other, which predicts a negligible effect.

Finally, as expected, all the models predict a steady increase in the volume fraction of the NiP plating with indentation depth, as shown in Fig. 23c. The strongest effect is exhibited by the Perriot-Barthel model, followed by those predicted by Bec et al. and Bull, Gao et al. and Antunes et al. (model 2), and Korsunsky-Constantinescu and Menčík et al. (model 2). The less strong substrate influence is predicted by the models of Antunes et al. (model 1), Menčík et al. (model 1) and Doerner and Nix.

The particular evolution that is observed for the volume fraction of each layer according to the different models that have been analyzed can be readily explained on the basis of the mixture law employed in each model, as well as the specific definition of such a fraction. As an example, the model advanced by Gao et al. [17] and the second model

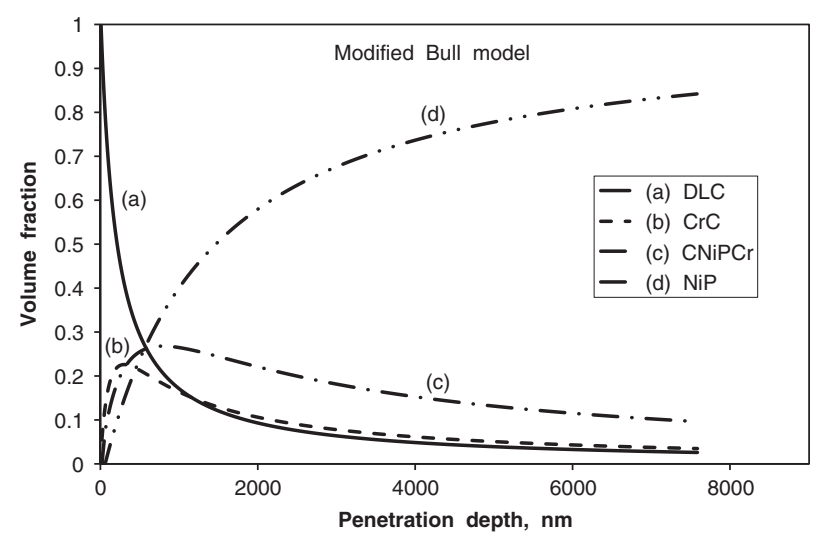

Fig. 21. Change in the volume fraction of each layer contributing to the composite elastic modulus, according to the modified Bull model, as a function of penetration depth.
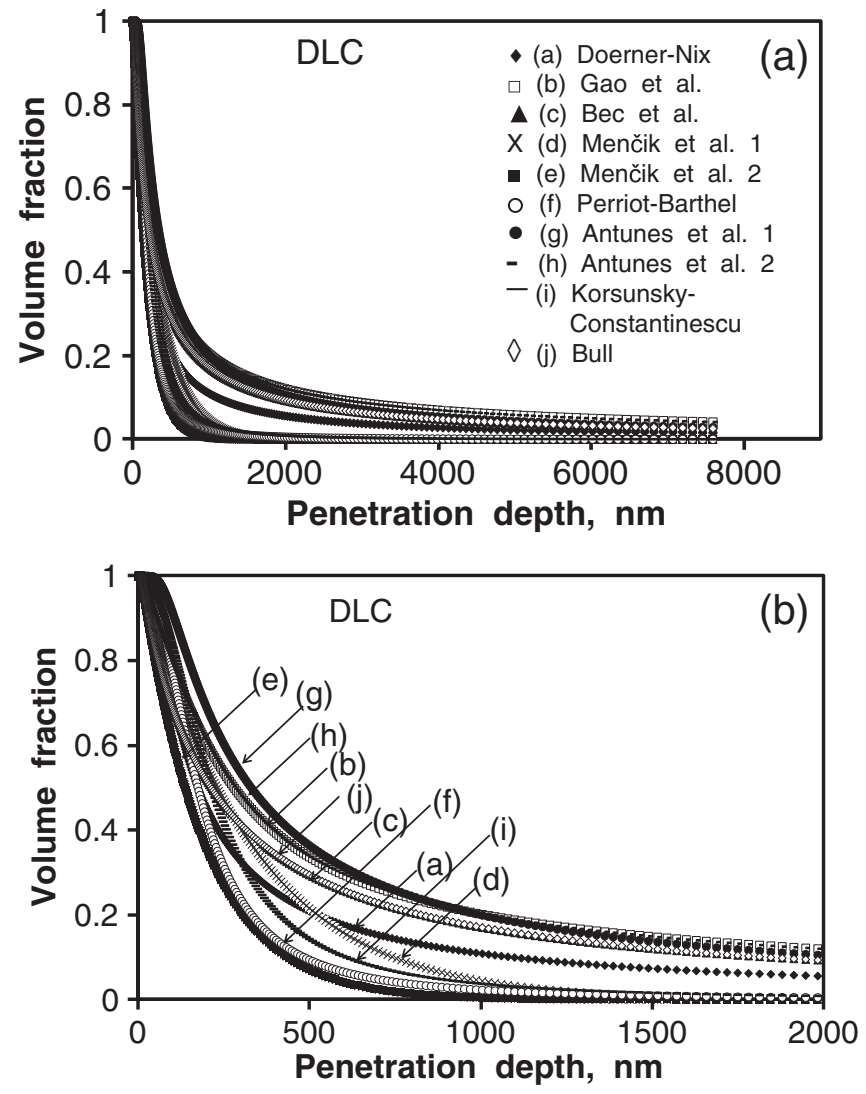

Fig. 22. Change in the volume fraction of the DLC layer as a function of penetration depth, according to each of the modified models analyzed in the present work.

proposed by Antunes et al. [20] employ the same weight function $\phi(\mathrm{h}$, $\left.t_{f}, v\right)$ indicated in Eq. ( $\left.5 b\right)$. However, Gao et al. model is based on a linear law of mixtures, whereas Antunes et al. model is based on a harmonic law. This simple fact gives rise to completely different results regarding the prediction of the volume fraction evolution for each layer, as well as for the computation of their corresponding elastic moduli.

A similar situation can be observed regarding the models advanced by Doerner and Nix [22] and the first model proposed by Antunes et al. [20]. Both models make used of the same weight function, as can be observed by comparing Eqs. (4b) and (10b). However, the Doerner and Nix model is based on a harmonic law of mixtures, whereas the first model proposed by Antunes et al. [20] is based on a linear law. As a consequence, the prediction of the volume fraction evolution for each layer according to each model is completely different, as well as the elastic moduli and the corresponding values of the constants $\alpha_{\mathrm{DN}}$ and $\alpha_{\mathrm{A} 1}$ found for each layer.

If the two models advanced by Menčík et al. [18] are compared with those proposed by Doerner and Nix [22] and Antunes et al. (model 1) [20], it can be readily understood why the predicted results are quite different in each case, despite the fact that the four models involve an exponential function with just one material parameter in their corresponding weight functions, as indicated by Eqs. (4b), (7b), (8b) and (10b). In this case, regardless of the type of mixture law employed in the model, the definition of the weight function in the form proposed by Menčík et al. [18], expressed in terms of $h / t_{f}$ rather than $t_{f} / h$ as in the Doerner and Nix and Antunes et al. (model 1) weight functions, will clearly lead to different results regarding the prediction of the volume fraction evolution and the computed parameters for each of the layers in the film.

The comparison of the model advanced by Perriot and Barthel [19] with that proposed by Korsunsky and Constantinescu [21] leads to similar conclusions. Both models assume the validity of a linear law of 

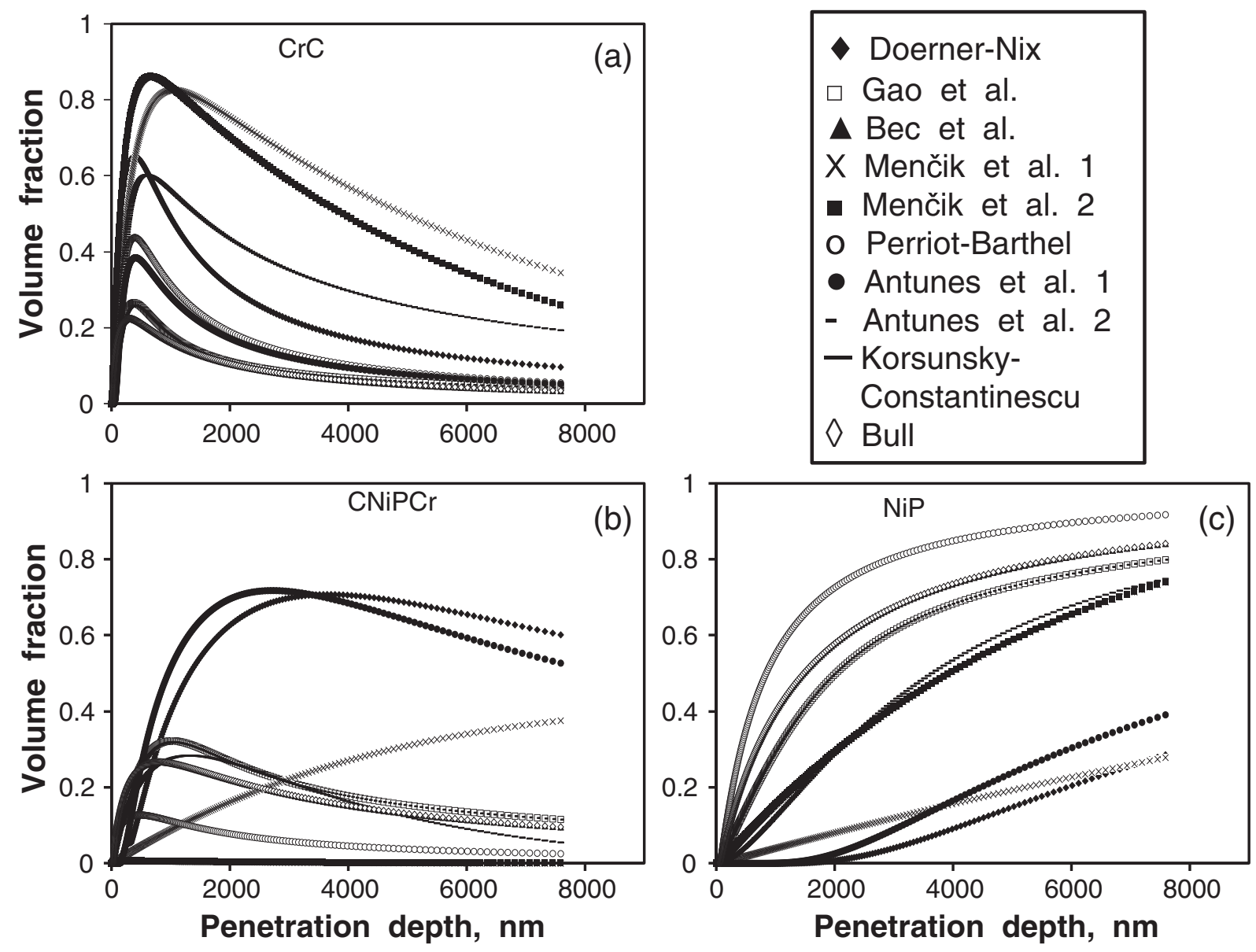

Fig. 23. Change in the volume fraction of the $\mathrm{CrC}, \mathrm{CNiPCr}$ and NiP layers as a function of penetration depth, according to each of the modified models analyzed in the present work.

mixtures. However, a close look at the corresponding weight functions, as indicated in Eqs. (9b) and (12b), points out that both models are bound to predict distinct volume fraction evolutions for each of the layers, despite that the number of material parameters involved in such functions is the same. In this case, it can again be observed that in the Perriot-Barthel model the weight function is expressed in terms of $t_{f} / h$ and is applied directly to the substrate modulus (Eq. (9a)), whereas in the Korsunsky-Constantinescu model the weight function is expressed in terms of $\mathrm{h} / \mathrm{t}_{\mathrm{f}}$ and it is applied directly to the film modulus (Eq. (12a)).

If a crude ranking of the different models is attempted based on the MSE, the magnitude of such a parameter would increase in the following order: Korsunsky-Constantinescu, Menčík et al. (model 2), Antunes et al. (model 1), Doerner and Nix, Perriot-Barthel, Gao et al., Menčík et al. (model 1), Bec et al., Bull and finally that of Antunes et al. (model 2, based on the Gao's et al. function, $\phi$ ). However, it is also important to take into consideration that the quality in the description of the experimental data fit partially increases as the number of parameters involved in the model also increases, which in turn leads to a decrease in the robustness of the model.

Thus, the most robust models are those which do not include any material parameter in their corresponding weight functions, such as those advanced by Gao et al., Bec et al., Antunes et al. (model 2) and Bull. In this case, the MSE is only influenced by the elastic modulus values corresponding to each of the layers, which compose the coating, as well as that of the substrate $(\mathrm{N}+1$ parameters, where $\mathrm{N}$ represents the number of layers). The next group would be that which includes the Doerner and Nix model, as well as the first model of Antunes et al. and the two models advanced by Menčík et al. These four approaches contain one material parameter in their corresponding weight functions and therefore the robustness is somewhat decreased. In this case, the MSE is also influenced by such material constants and therefore, the number of parameters which intervene in the numerical procedure increases to $2 \mathrm{~N}+1$. Finally, the less robust models would be those proposed by Perriot-Barthel and Korsunsky-Constantinescu, which include two material constants in their corresponding weight functions, which are strongly correlated between them. In this way, the MSE would be influenced by $3 \mathrm{~N}+1$ parameters.

Concerning the values of the elastic modulus predicted by the different models for the distinct layers, which encompass the multilayer coating, the magnitude of $69 \pm 3 \mathrm{GPa}$ found for the DLC film is somewhat less than the expected value for this type of coating, in the range of 100-300 GPa, as reported by Lemoine et al. [45]. However, as shown in Fig. 1, these results cannot be attributed to a blunted tip indenter employed in the nanoindentation tests but rather, to the structure and defects present in the film. As indicated by the Lemoine and coworkers [45], the mechanical behavior of DLC films is not only determined by the organization of the material at the micro or nanoscale, presence of fibers or thin films and $\mathrm{sp}^{3}$ fraction, but also by the defects present in numerous forms, including network terminations, bond angle disorder and impurities.

The elastic modulus predicted for the $\mathrm{CrC}$ layer of approximately $135 \pm 17 \mathrm{GPa}$ is well in the range of 100-152 GPa reported by Anderson et al. [46] for $\mathrm{CrC}$ films deposited by means of non-reactive direct current (DC) magnetron sputtering, with a carbon content spanning 85-67 at.\%. These authors reported that the mechanical properties of the investigated $\mathrm{Cr}-\mathrm{C}$ films depended strongly on the carbon content and that the elastic modulus could achieve values between 256-346 GPa for a carbon content of 25 at.\%, depending on their condition. 
On the other hand, the elastic modulus predicted for the $\mathrm{CNiPCr}$ layer of approximately $144 \pm 5 \mathrm{GPa}$ is very close, as expected, to that of the NiP "substrate" of $146 \pm 2 \mathrm{GPa}$. The graded nature of the CNiPCr has been analyzed in detail by Staia et al. [39], who described the changes in $\mathrm{C}, \mathrm{Cr}$, Ni and $\mathrm{P}$ that take place within this layer by means of EPMA techniques conducted on the cross section of the coated system. These results showed clearly that during PVD deposition diffusion of $\mathrm{C}$ and $\mathrm{Cr}$ took place from the $\mathrm{CrC}$ layer towards the NiP plating, whereas diffusion of $\mathrm{Ni}$ and $\mathrm{P}$ also occurred from the NiP deposit towards the $\mathrm{CrC}$ film. Staia and co-workers [39] showed that this diffusion process gave rise to the formation of such a graded layer, which for simplicity, as far as the present investigation is concerned, has been considered as an additional layer with "homogeneous" mechanical properties. However, it is acknowledged that such an assumption is an over simplification of this complex problem, whose formal analysis would require the consideration of the continuous change in mechanical properties that actually occurs throughout the layer.

Further evidence of the correct trend in the computation of the elastic modulus by means of the different models analyzed in the present work is given in Figs. 24 and 25, corresponding to the modeling of the experimental data reported by Bull [25] for a bilayer $\mathrm{Cu} /$ silica/silicon system. Fig. 24 illustrates the prediction of the change in contact modulus as a function of contact depth provided by the different models investigated, assuming that $\mathrm{E}_{\mathrm{Cu}}=120 \mathrm{GPa}, \mathrm{E}_{\text {silica }}=70 \mathrm{GPa}$ and $\mathrm{E}_{\text {silicon }}=167 \mathrm{GPa}$, and taking into account that $\mathrm{t}_{\mathrm{Cu}}=800 \mathrm{~nm}$ and $\mathrm{t}_{\text {silica }}=1000 \mathrm{~nm}$, as indicated by Bull [25]. This figure clearly shows that most of the extended models are able to provide a very satisfactory description of the experimental data, with the exception of the second model advanced by Antunes et al. [20], which is based on Gao's et al. function. In this case, it was assumed that $v_{\mathrm{Cu}}=0.355$ and $v_{\text {silica }}=$ 0.17 . Given the fact that the different extended models are based on the $1 \%$ layer thickness rule, for contact depths less than $8 \mathrm{~nm}$, a prediction of a constant contact modulus equal to $120 \mathrm{GPa}(\mathrm{Cu})$ is obtained. As the contact depth increases between 8 and $18 \mathrm{~nm}$ the contact modulus is determined by both the $\mathrm{Cu}$ and silica layers, which gives rise to a decrease in its magnitude, as shown in the figure. For contact depths greater than $18 \mathrm{~nm}$, the influence of the silicon substrate becomes important and the predicted value of the contact modulus reaches a minimum and increases again, as observed on the plot.

On the other hand, Fig. 25 illustrates the comparison of the prediction results reported by Bull [25] and those obtained with the extended model proposed in the present work. As can be observed from this figure both predictions compare very well. This observation gives further support to the physical basis on which the different models have been

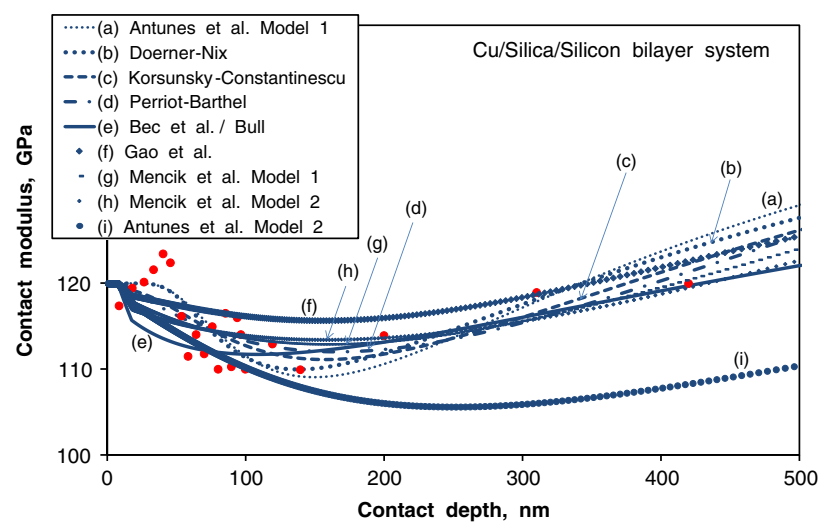

Fig. 24. Change in the contact modulus as a function of contact depth for the bilayer $\mathrm{Cu} / \mathrm{sil}-$ ica/silicon system, as predicted by the different extended models analyzed in the present work. The experimental data (red dots) have been reported by Bull [25]. $\mathrm{E}_{\mathrm{Cu}}=120 \mathrm{GPa}$, $\mathrm{E}_{\text {silica }}=70 \mathrm{GPa}, \mathrm{E}_{\text {silicon }}=167 \mathrm{GPa}, \mathrm{t}_{\mathrm{Cu}}=800 \mathrm{~nm}$ and $\mathrm{t}_{\text {silica }}=1000 \mathrm{~nm}$.

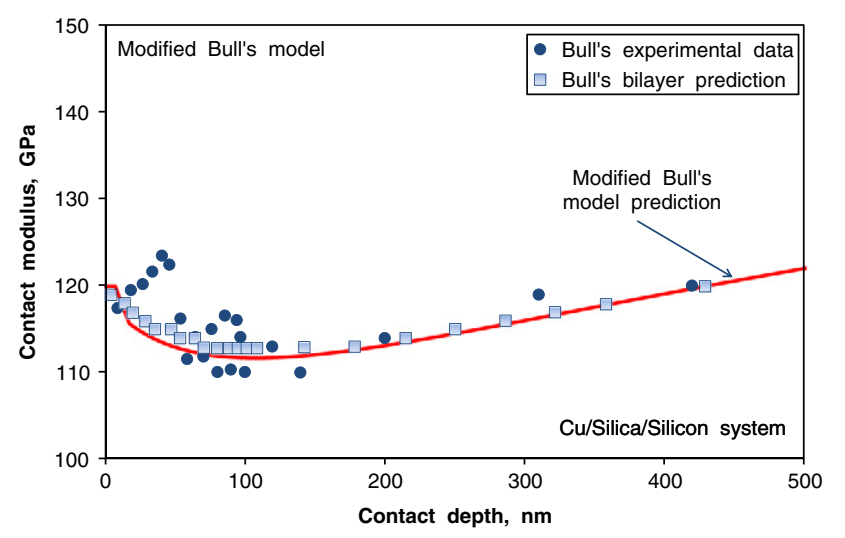

Fig. 25. Comparison of the predictions in the change of the contact modulus as a function of contact depth for the bilayer $\mathrm{Cu}$ /silica/silicon system, corresponding to the extended Bull's model proposed in the present work and that reported by Bull [25].

extended to analyze the elastic modulus of the distinct layers encompassing a multilayer coating.

A final important aspect that should be mentioned regarding the trilayer system investigated in the present work is that related to the change in the composite elastic modulus with penetration depth and the expected influence of the aluminum alloy actual substrate. According to the "rule" of the $1 \%$ of the coating thickness, applied for the evaluation of the elastic response of coated systems and taking into consideration that the overall thickness of the multilayer coating is of approximately $54 \mu \mathrm{m}$, the aluminum alloy substrate, with a elastic modulus of approximately $76 \mathrm{GPa}$, should start contributing to such a response at penetration depths in the range of $540 \mathrm{~nm}$. Such a contribution would be recognized on the composite elastic modulus curve as a significant decline in its value. However, as can be observed from the elastic modulus versus penetration depth plot, even at penetration depths close to $7000 \mathrm{~nm}$ this influence is not perceived at all. Moreover, if the hypothesis that the aluminum alloy substrate will start to contribute to the composite modulus at a penetration depth of $540 \mathrm{~nm}$ is made, the different models that have been analyzed would predict a negligible volume fraction of such a material and therefore, no contribution whatsoever to the composite modulus. This observation points out the highly localized nature of the stress field below the indenter, which somehow should also be included into the multilayer formalism. Therefore, indentation experiments at higher maximum loads are being conducted for determining more precisely the penetration depth at which the aluminum alloy substrate effects will be actually perceived.

\section{Conclusions}

A rational methodology, which allows the description of the change in the composite elastic modulus with indentation depth for multilayer coatings, has been developed. The formalism involves the extension of the different models proposed for monolayer coatings, in order to analyze the complex behavior exhibited by multilayer coatings under indentation loading. The proposed methodology is founded on the physically-based concept advanced by lost et al. [32], which allows the computation of the volume fraction of each layer in the coating and therefore, its contribution to the elastic response of the coating. It has been shown that such a volume fraction can be determined from the weight function employed either in the linear or harmonic laws used for describing the composite elastic modulus measured as a function of the indentation depth. In order to illustrate the applicability of the formalism, a number of models proposed in the literature for the description of the composite elastic modulus of monolayer coatings have been modified and extended for the analysis of a multilayer coating. These models include those advanced by Gao et al. [17], Menčík 
et al. [18], Perriot and Barthel [19], Antunes et al. [20], Korsunsky and Constantinescu [21], Doerner and Nix [22], Bec et al. [23] and Bull [24, 25]. The coated system that has been analyzed corresponds to a 2024T6 aluminum alloy with a multilayer coating of DLC/CrC/CNiPCr/NiP of approximately $54 \mu \mathrm{m}$ in thickness. It has been found that the different models analyzed provide a satisfactory description of the elastic modulus as a function of penetration depth, both for the trilayer system investigated in the present work, as well as for a set of experimental data reported in the literature for a bilayer coated system [25]. However, as expected, the quality of the fit increases as the number of material parameters involved in the model also increases. A crude comparison between the models can be carried out on the basis of the mean square error.

\section{Acknowledgments}

Professor E. S. Puchi-Cabrera gratefully acknowledges the financial support of the Conseil Régional Nord-Pas de Calais, France, through the International Chair program 2011, as well as the CDCH-UCV through the project PG-08-7775-2009/2. Professor Staia also acknowledges the financial support of the Scientific and Humanistic Development Council of the Universidad Central de Venezuela ( $\mathrm{CDCH}-\mathrm{UCV}$ ) through project AIB-08-8539-2012 and to Arts et Métiers Paris Tech (ENSAM Lille), France.

Appendix 11. Formulation corresponding to the model advanced by Gao et al. [17]

As indicated in Section 2, for this model the composite elastic modulus can be expressed as:

$\mathrm{E}_{\mathrm{C}}=\mathrm{a}_{\mathrm{G}}\left(\mathrm{t}_{\mathrm{f}} / \mathrm{h}\right) \mathrm{E}_{\mathrm{F}}+\left(1-\mathrm{a}_{\mathrm{G}}\left(\mathrm{t}_{\mathrm{f}} / \mathrm{h}\right)\right) \mathrm{E}_{\mathrm{S}}$

where:

$$
\begin{aligned}
& \mathrm{a}_{\mathrm{G}}\left(\mathrm{t}_{\mathrm{f}} / \mathrm{h}\right)=\phi\left(\mathrm{h}, \mathrm{t}_{\mathrm{f}}, v\right)=\frac{2}{\pi} \tan ^{-1}\left(\frac{\mathrm{t}_{\mathrm{f}}}{\mathrm{h} \tan \psi}\right)+ \\
& \frac{1}{2 \pi(1-v)}\left\{(1-2 v) \frac{\mathrm{t}_{\mathrm{f}}}{\mathrm{h} \tan \psi} \ln \left[1+\left(\frac{\mathrm{h} \tan \psi}{\mathrm{t}_{\mathrm{f}}}\right)^{2}-\frac{\left(\frac{\mathrm{h} \tan \psi}{\mathrm{t}_{\mathrm{f}}}\right)}{1+\left(\frac{\mathrm{h} \tan \psi}{\mathrm{t}_{\mathrm{f}}}\right)^{2}}\right]\right\} .
\end{aligned}
$$

For extending the model to multilayer coatings:

$$
\begin{aligned}
\mathrm{x}_{\mathrm{v}}^{(1)}= & \phi\left[\mathrm{h}-\frac{\mathrm{t}_{\mathrm{f}}^{(1)}}{100}, \mathrm{t}_{\mathrm{f}}^{(1)}, v^{(1)}\right] \quad \text { if } \mathrm{h}>\frac{\mathrm{t}_{\mathrm{f}}^{(1)}}{100} \text { and } \\
\mathrm{x}_{\mathrm{v}}^{(\mathrm{j})}= & \phi\left[\mathrm{h}-\frac{1}{100} \sum_{\mathrm{i}=1}^{\mathrm{j}} \mathrm{t}_{\mathrm{f}}^{(\mathrm{i})}, \sum_{\mathrm{i}=1}^{\mathrm{j}} \mathrm{t}_{\mathrm{f}}^{(\mathrm{i})}, v^{(\mathrm{j})}\right] \\
& -\phi\left[\mathrm{h}-\frac{1}{100} \sum_{\mathrm{i}=1}^{\mathrm{j}-1} \mathrm{t}_{\mathrm{f}}^{(\mathrm{i})}, \sum_{\mathrm{i}=1}^{\mathrm{j}-1} \mathrm{t}_{\mathrm{f}}^{(\mathrm{i})}, v^{(\mathrm{j}-1)}\right] \quad \text { if } \quad \mathrm{h}>\frac{1}{100} \sum_{\mathrm{i}=1}^{\mathrm{j}} \mathrm{t}_{\mathrm{f}}^{(\mathrm{i})} .
\end{aligned}
$$

Finally:

$$
\mathrm{E}_{\mathrm{C}}=\sum_{\mathrm{i}=1}^{\mathrm{N}} \mathrm{x}_{\mathrm{v}}{ }^{(\mathrm{i})} \mathrm{E}_{\mathrm{F}}{ }^{(\mathrm{i})}+\mathrm{x}_{\mathrm{v}}{ }^{(\mathrm{S})} \mathrm{E}_{\mathrm{S}}
$$

The model requires the determination of $\mathrm{N}+1$ parameters.

\section{Formulation corresponding to the first model advanced by Bec et al. [23]}

As indicated in Section 2, according to this model:

$\frac{1}{\mathrm{E}_{\mathrm{C}}}=\frac{\mathrm{a}_{\mathrm{Bec}}\left(\mathrm{t}_{\mathrm{f}}, \mathrm{a}, \mathrm{h}\right)}{\mathrm{E}_{\mathrm{F}}}+\frac{1-\mathrm{a}_{\mathrm{Bec}}\left(\mathrm{t}_{\mathrm{f}}, \mathrm{a}, \mathrm{h}\right)}{\mathrm{E}_{\mathrm{S}}}$

where:

$\mathrm{a}_{\mathrm{Bec}}\left(\mathrm{t}_{\mathrm{f}}, \mathrm{a}, \mathrm{h}\right)=\frac{2 \mathrm{t}_{\mathrm{f}}}{\pi \mathrm{a}\left(1+\frac{2 \mathrm{t}_{\mathrm{f}}}{\pi \mathrm{a}}\right)}=\frac{2 \mathrm{t}_{\mathrm{f}}}{\pi \mathrm{h} \tan \psi\left(1+\frac{2 \mathrm{t}_{\mathrm{f}}}{\pi \mathrm{h} \tan \psi}\right)}$.

The extension of the model to multilayer coatings requires that:

$$
\begin{aligned}
\mathrm{x}_{\mathrm{v}}^{(1)}= & \frac{2 \mathrm{t}_{\mathrm{f}}^{(1)}}{\left.\pi \mathrm{h}-\frac{\mathrm{t}_{\mathrm{f}}^{(1)}}{100}\right) \tan (\psi)+2 \mathrm{t}_{\mathrm{f}}{ }^{(1)}} \text { if } \mathrm{h}>\frac{\mathrm{t}_{\mathrm{f}}{ }^{(1)}}{100} \text { and } \\
\mathrm{x}_{\mathrm{v}}^{(\mathrm{j})}= & \frac{2 \sum_{\mathrm{i}=1}^{\mathrm{j}} \mathrm{t}_{\mathrm{f}}^{(\mathrm{j})}}{\left.\mathrm{h}-\frac{1}{100} \sum_{\mathrm{i}=1}^{\mathrm{j}} \mathrm{t}_{\mathrm{f}}^{(\mathrm{j})}\right) \tan (\psi)+2 \sum_{\mathrm{i}=1}^{\mathrm{j}} \mathrm{t}_{\mathrm{f}}{ }^{(\mathrm{j})}} \\
& -\frac{2 \sum_{\mathrm{i}=1}^{\mathrm{j}-1} \mathrm{t}_{\mathrm{f}}^{(\mathrm{j})}}{\left.\mathrm{h}-\frac{1}{100} \sum_{\mathrm{i}=1}^{\mathrm{j}-1} \mathrm{t}_{\mathrm{f}}^{(\mathrm{j})}\right) \tan (\psi)+2 \sum_{\mathrm{i}=1}^{\mathrm{j}-1} \mathrm{t}_{\mathrm{f}}{ }^{(\mathrm{j})}} \text { if } \mathrm{h}>\frac{1}{100} \sum_{\mathrm{i}=1}^{\mathrm{j}} \mathrm{t}_{\mathrm{f}}^{(\mathrm{i})}
\end{aligned}
$$

$\frac{1}{E_{C}}=\sum_{i=1}^{N} \frac{x_{v}{ }^{(i)}}{E_{F}^{(i)}}+\frac{x_{v}^{(S)}}{E_{S}}$.

The model requires the determination of $\mathrm{N}+1$ parameters.

3. Formulation corresponding to the first model advanced by Menčík et al. [18]

As indicated in Section 2, according to this model:

$\mathrm{E}_{\mathrm{C}}=\mathrm{a}_{\mathrm{M} 1}\left(\alpha_{\mathrm{M} 1}, \mathrm{t}_{\mathrm{f}} / \mathrm{h}\right) \mathrm{E}_{\mathrm{F}}+\left(1-\mathrm{a}_{\mathrm{M} 1}\left(\alpha_{\mathrm{M} 1}, \mathrm{t}_{\mathrm{f}} / \mathrm{h}\right)\right) \mathrm{E}_{\mathrm{S}}$

where:

$\mathrm{a}_{\mathrm{M} 1}\left(\alpha_{\mathrm{M} 1}, \mathrm{t}_{\mathrm{f}} / \mathrm{h}\right)=\exp \left[-\alpha_{\mathrm{M} 1} \frac{\mathrm{h}}{\mathrm{t}_{\mathrm{f}}}\right]$.

For extending the model to multilayer coatings:

$\mathrm{x}_{\mathrm{v}}{ }^{(1)}=\exp \left[-\alpha_{\mathrm{M} 1}{ }^{(1)} \frac{\mathrm{h}-\frac{\mathrm{t}_{\mathrm{f}}{ }^{(1)}}{100}}{\mathrm{t}_{\mathrm{f}}{ }^{(1)}}\right]$ if $\mathrm{h}>\frac{\mathrm{t}_{\mathrm{f}}{ }^{(1)}}{100}$ and 


$$
\begin{aligned}
\mathrm{x}_{\mathrm{v}}{ }^{(\mathrm{j})}= & \exp \left[-\alpha_{\mathrm{M} 1}{ }^{(\mathrm{j})} \frac{\mathrm{h}-\frac{1}{100} \sum_{\mathrm{i}=1}^{\mathrm{j}} \mathrm{t}_{\mathrm{f}}{ }^{(\mathrm{i})}}{\sum_{\mathrm{i}=1}^{\mathrm{j}} \mathrm{t}_{\mathrm{f}}^{\left({ }^{(i)}\right.}}\right] \\
& -\exp \left[-\alpha_{\mathrm{M} 1}{ }^{(\mathrm{j}-1)} \frac{\mathrm{h}-\frac{1}{100} \sum_{\mathrm{i}=1}^{\mathrm{j}-1} \mathrm{t}_{\mathrm{f}}{ }^{(\mathrm{i})}}{\sum_{\mathrm{i}=1}^{\mathrm{j}-1} \mathrm{t}_{\mathrm{f}}{ }^{(\mathrm{i})}}\right] \text { if } \mathrm{h}>\frac{1}{100} \sum_{\mathrm{i}=1}^{\mathrm{j}} \mathrm{t}_{\mathrm{f}}{ }^{(\mathrm{i})} .
\end{aligned}
$$

Finally:

$$
\mathrm{E}_{\mathrm{C}}=\sum_{\mathrm{i}=1}^{\mathrm{N}} \mathrm{x}_{\mathrm{v}}{ }^{(\mathrm{i})} \mathrm{E}_{\mathrm{F}}{ }^{(\mathrm{i})}+\mathrm{x}_{\mathrm{v}}{ }^{(\mathrm{S})} \mathrm{E}_{\mathrm{S}} .
$$

The model requires the determination of $2 \mathrm{~N}+1$ parameters.

4. Formulation corresponding to the second model advanced by Menčík et al. [18]

As indicated in Section 2, according to this second model:

$\frac{1}{\mathrm{E}_{\mathrm{C}}}=\frac{\mathrm{a}_{\mathrm{M} 2}\left(\alpha_{\mathrm{M} 2}, \mathrm{t}_{\mathrm{f}} / \mathrm{h}\right)}{\mathrm{E}_{\mathrm{F}}}+\frac{1-\mathrm{a}\left(\alpha_{\mathrm{M} 2}, \mathrm{t}_{\mathrm{f}} / \mathrm{h}\right)}{\mathrm{E}_{\mathrm{S}}}$

where, again:

$\mathrm{a}_{\mathrm{M} 2}\left(\alpha_{\mathrm{M} 2}, \mathrm{t}_{\mathrm{f}} / \mathrm{h}\right)=\exp \left[-\alpha_{\mathrm{M} 2} \frac{\mathrm{h}}{\mathrm{t}_{\mathrm{f}}}\right]$.

For extending the model to multilayer coatings:

$$
\begin{aligned}
\mathrm{x}_{\mathrm{v}}{ }^{(1)}= & \exp \left[-\alpha_{\mathrm{M} 2}{ }^{(1)} \frac{\mathrm{h}-\frac{\mathrm{t}_{\mathrm{f}}{ }^{(1)}}{100}}{\mathrm{t}_{\mathrm{f}}{ }^{(1)}}\right] \text { if } \mathrm{h}>\frac{\mathrm{t}_{\mathrm{f}}{ }^{(1)}}{100} \text { and } \\
\mathrm{x}_{\mathrm{v}}{ }^{(\mathrm{j})}= & \exp \left[-\alpha_{\mathrm{M} 2}{ }^{(\mathrm{j})} \frac{\mathrm{h}-\frac{1}{100} \sum_{\mathrm{i}=1}^{\mathrm{j}} \mathrm{t}_{\mathrm{f}}{ }^{(\mathrm{i})}}{\sum_{\mathrm{i}=1}^{\mathrm{j}} \mathrm{t}_{\mathrm{f}}^{\left({ }^{(i)}\right.}}\right] \\
& -\exp \left[-\alpha_{\mathrm{M} 2}{ }^{(\mathrm{j}-1)} \frac{\mathrm{h}-\frac{1}{100} \sum_{\mathrm{i}=1}^{\mathrm{j}-1} \mathrm{t}_{\mathrm{f}}^{\left({ }^{(i)}\right.}}{\sum_{\mathrm{i}=1}^{\mathrm{j}-1} \mathrm{t}_{\mathrm{f}}^{(\mathrm{i})}}\right] \text { if } \mathrm{h}>\frac{1}{100} \sum_{\mathrm{i}=1}^{\mathrm{j}} \mathrm{t}_{\mathrm{f}}^{\left({ }^{(i)}\right.} .
\end{aligned}
$$

Finally:

$$
\frac{1}{\mathrm{E}_{\mathrm{C}}}=\sum_{\mathrm{i}=1}^{\mathrm{N}} \frac{\mathrm{x}_{\mathrm{v}}{ }^{(\mathrm{i})}}{\mathrm{E}_{\mathrm{F}}{ }^{(\mathrm{i})}}+\frac{\mathrm{x}_{\mathrm{v}}{ }^{(\mathrm{S})}}{\mathrm{E}_{\mathrm{S}}} .
$$

The model would also require the determination of $2 \mathrm{~N}+1$ parameters.

\section{Formulation corresponding to the model advanced by Perriot and Barthel} [19]

As indicated in Section 2, according to this model:

$\mathrm{E}_{\mathrm{C}}=\left[1-\mathrm{a}_{\mathrm{PB}}\left(\beta_{\mathrm{PB}}, \mathrm{n}_{\mathrm{PB}}, \mathrm{t}_{\mathrm{f}} / \mathrm{h}\right)\right] \mathrm{E}_{\mathrm{F}}+\mathrm{a}_{\mathrm{PB}}\left(\beta_{\mathrm{PB}}, \mathrm{n}_{\mathrm{PB}}, \mathrm{t}_{\mathrm{f}} / \mathrm{h}\right) \mathrm{E}_{\mathrm{S}}$ where:

$\mathrm{a}_{\mathrm{PB}}\left(\beta_{\mathrm{PB}}, \mathrm{n}_{\mathrm{PB}}, \mathrm{t}_{\mathrm{f}} / \mathrm{h}\right)=\frac{1}{1+\left(\frac{\beta_{\mathrm{p}} \mathrm{t}_{\mathrm{f}}}{\mathrm{ht} \tan \psi}\right)^{\mathrm{n}_{\mathrm{PB}}}}$. that:

Thus, the extension of the model to multilayer coatings requires $\mathrm{x}_{\mathrm{v}}{ }^{(1)}=1-\frac{1}{1+\left(\frac{\beta_{\mathrm{pg}}(1) \mathrm{t}_{\mathrm{f}}^{(1)}}{\left(\mathrm{h}-\frac{\mathrm{f}^{(1)}}{\mathrm{f} 00 \mathrm{~d}}\right) \tan \psi}\right)^{\mathrm{n}_{\mathrm{pg}}(1)}}$ if $\mathrm{h}>\frac{\mathrm{t}_{\mathrm{f}}^{(1)}}{100}$ and

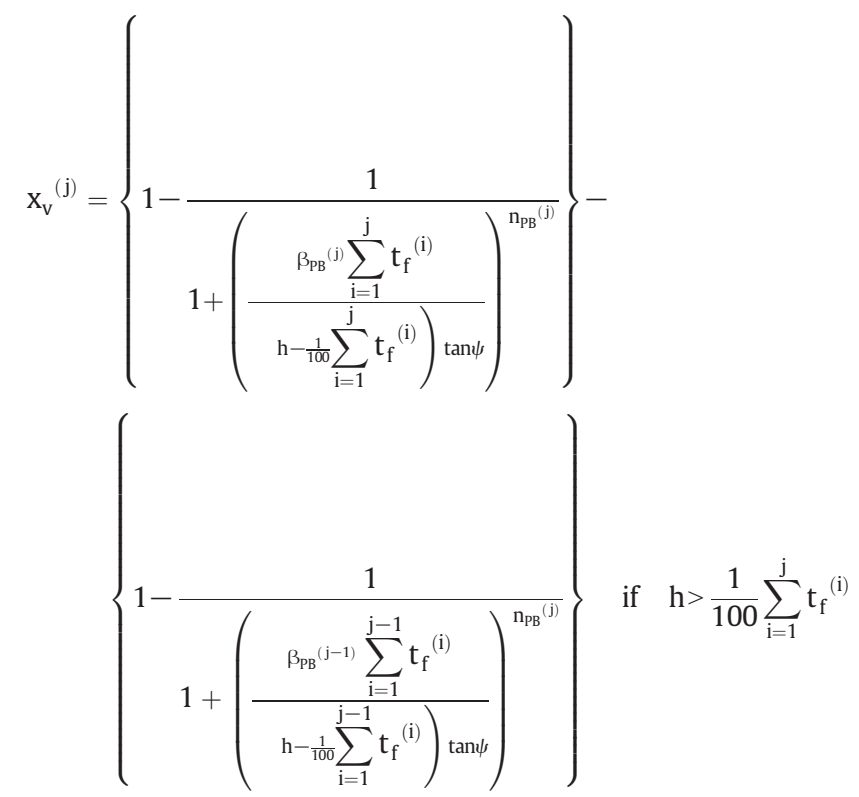

$\mathrm{E}_{\mathrm{C}}=\sum_{\mathrm{i}=1}^{\mathrm{N}} \mathrm{x}_{\mathrm{v}}{ }^{(\mathrm{i})} \mathrm{E}_{\mathrm{F}}{ }^{(\mathrm{i})}+\mathrm{x}_{\mathrm{v}}{ }^{(\mathrm{S})} \mathrm{E}_{\mathrm{S}}$

The model would require the determination of $3 \mathrm{~N}+1$ parameters.

6. Formulation corresponding to the first model advanced by Antunes et al. [20]

As pointed out in Section 2, according to this model:

$\mathrm{E}_{\mathrm{C}}=\left[1-\mathrm{a}_{\mathrm{A} 1}\left(\alpha_{\mathrm{A} 1}, \mathrm{t}_{\mathrm{f}} / \mathrm{h}\right)\right] \mathrm{E}_{\mathrm{F}}+\mathrm{a}_{\mathrm{A} 1}\left(\alpha_{\mathrm{A} 1}, \mathrm{t}_{\mathrm{f}} / \mathrm{h}\right) \mathrm{E}_{\mathrm{S}}$

where:

$a_{A 1}\left(\alpha_{A 1}, t_{f} / h\right)=\exp \left(-\alpha_{A 1} \frac{t_{f}}{h}\right)$.

Thus, the extension of the model to multilayer coatings requires that:

$$
\begin{aligned}
\mathrm{x}_{\mathrm{v}}^{(1)} & =\mathrm{a}_{\mathrm{A} 1}{ }^{(1)} \\
& =\left\{1-\exp \left(-\alpha_{\mathrm{A} 1}{ }^{(1)} \frac{\mathrm{t}_{\mathrm{f}}{ }^{(1)}}{\mathrm{h}-\frac{\mathrm{t}_{\mathrm{f}}{ }^{(1)}}{100}}\right)\right\} \text { if } \mathrm{h}>\frac{\mathrm{t}_{\mathrm{f}}{ }^{(1)}}{100} \text { and }
\end{aligned}
$$


$\begin{aligned} \mathrm{x}_{\mathrm{v}}{ }^{(\mathrm{j})}= & \left\{1-\exp \left(-\alpha_{\mathrm{A} 1}{ }^{(\mathrm{j})} \frac{\sum_{\mathrm{i}=1}^{\mathrm{j}} \mathrm{t}_{\mathrm{f}}{ }^{(\mathrm{i})}}{\mathrm{h}-\frac{1}{100} \sum_{\mathrm{i}=1}^{\mathrm{j}} \mathrm{t}_{\mathrm{f}}{ }^{(\mathrm{i})}}\right)\right\} \\ & -\left\{1-\exp \left(-\alpha_{\mathrm{A} 1}{ }^{(\mathrm{j}-1)} \frac{\sum_{\mathrm{i}=1}^{\mathrm{j}-1} \mathrm{t}_{\mathrm{f}}{ }^{(\mathrm{i})}}{\mathrm{h}-\frac{1}{100} \sum_{\mathrm{i}=1}^{\mathrm{j}-1} \mathrm{t}_{\mathrm{f}}{ }^{(\mathrm{i})}}\right)\right\} \text { if } \mathrm{h}>\frac{1}{100} \sum_{\mathrm{i}=1}^{\mathrm{j}} \mathrm{t}_{\mathrm{f}}{ }^{(\mathrm{i})}\end{aligned}$

$\mathrm{E}_{\mathrm{C}}=\sum_{\mathrm{i}=1}^{\mathrm{N}} \mathrm{x}_{\mathrm{v}}{ }^{(\mathrm{i})} \mathrm{E}_{\mathrm{F}}{ }^{(\mathrm{i})}+\mathrm{x}_{\mathrm{v}}^{\left({ }^{(S)}\right.} \mathrm{E}_{\mathrm{S}}$

The model would require the determination of $2 \mathrm{~N}+1$ parameters.

7. Formulation corresponding to the second model advanced by Antunes et al. [20]

As indicated in Section 2, according to this model:

$\frac{1}{E_{C}}=\frac{a_{A 2}\left(t_{f} / h\right)}{E_{F}}+\frac{1-a_{A 2}\left(t_{f} / h\right)}{E_{S}}$

where:

$\mathrm{a}_{\mathrm{A} 2}\left(\mathrm{t}_{\mathrm{f}} / \mathrm{h}_{\mathrm{h}}\right)=\phi\left(\mathrm{h}, \mathrm{t}_{\mathrm{f}}, \mathrm{v}\right)$.

The extension of the model to multilayer coatings is conducted by means of Eqs. (A3) and (A4). Finally:

$\frac{1}{\mathrm{E}_{\mathrm{C}}}=\sum_{\mathrm{i}=1}^{\mathrm{N}} \frac{\mathrm{X}_{\mathrm{v}}{ }^{(\mathrm{i})}}{\mathrm{E}_{\mathrm{F}}{ }^{(\mathrm{i})}}+\frac{\mathrm{X}_{\mathrm{v}}{ }^{(\mathrm{S})}}{\mathrm{E}_{\mathrm{S}}}$.

As the model advanced by Gao et al. [17], this model also requires the determination of $\mathrm{N}+1$ parameters.

8. Formulation corresponding to the model advanced by Korsunsky and Constantinescu [21]

As pointed out in Section 2, according to this model:

$\mathrm{E}_{\mathrm{C}}=\mathrm{a}_{\mathrm{KC}}\left(\beta_{\mathrm{KC}}, \mathrm{n}_{\mathrm{KC}}, \mathrm{t}_{\mathrm{f}} / \mathrm{h}\right) \mathrm{E}_{\mathrm{F}}+\left[1-\mathrm{a}_{\mathrm{KC}}\left(\beta_{\mathrm{KC}}, \mathrm{n}_{\mathrm{KC}}, \mathrm{t}_{\mathrm{f}} / \mathrm{h}\right)\right] \mathrm{E}_{\mathrm{S}}$

where:

$\mathrm{a}_{\mathrm{KC}}\left(\beta_{\mathrm{KC}}, \mathrm{n}_{\mathrm{KC}}, \mathrm{t}_{\mathrm{f}} / \mathrm{h}\right)=\frac{1}{1+\left(\frac{\mathrm{h}}{\beta_{\mathrm{KC}} \mathrm{t}_{\mathrm{f}}}\right)^{\mathrm{n}_{\mathrm{KC}}}}$.

Thus, the extension of the model to multilayer coatings requires that:

$\mathrm{x}_{\mathrm{V}}^{(1)}=\frac{1}{1+\left[\frac{\left(\mathrm{h}-\frac{\mathrm{t}_{\mathrm{f}}^{(1)}}{100}\right)}{\beta_{\mathrm{KC}}{ }^{(1)} \mathrm{t}_{\mathrm{f}}^{(1)}}\right]^{\mathrm{n}_{\mathrm{KC}}(1)}} \quad$ if $\mathrm{h}>\frac{\mathrm{t}_{\mathrm{f}}^{(1)}}{100}$ and

$$
\begin{aligned}
& \mathrm{x}_{\mathrm{v}}^{(\mathrm{j})}=\frac{1}{1+\left[\frac{\left.\mathrm{h}-\frac{1}{100} \sum_{\mathrm{i}=1}^{\mathrm{j}} \mathrm{t}_{\mathrm{f}}{ }^{(\mathrm{i})}\right)}{\beta_{\mathrm{KC}}{ }^{(\mathrm{j})} \sum_{\mathrm{i}=1}^{\mathrm{j}} \mathrm{t}_{\mathrm{f}}{ }^{(\mathrm{i})}}\right]^{\mathrm{n}_{\mathrm{KC}}{ }^{(\mathrm{j})}}}
\end{aligned}
$$

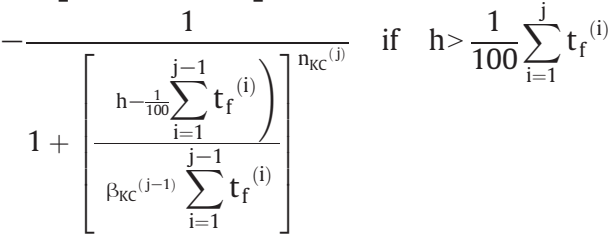

$$
\begin{aligned}
& \mathrm{E}_{\mathrm{C}}=\sum_{\mathrm{i}=1}^{\mathrm{N}} \mathrm{x}_{\mathrm{v}}{ }^{(\mathrm{i})} \mathrm{E}_{\mathrm{F}}{ }^{(\mathrm{i})}+\mathrm{x}_{\mathrm{v}}{ }^{(\mathrm{S})} \mathrm{E}_{\mathrm{S}} \text {. }
\end{aligned}
$$

The model requires the determination of $3 \mathrm{~N}+1$ parameters.

\section{Formulation corresponding to the model advanced by Bull $[23,24]$}

As indicated in Section 2, according to this model:

$\frac{1}{\mathrm{E}_{\mathrm{C}}}=\frac{1-\mathrm{a}_{\mathrm{B}}\left(\mathrm{t}_{\mathrm{f}} / \mathrm{h}\right)}{\mathrm{E}_{\mathrm{F}}}+\frac{\mathrm{a}_{\mathrm{B}}\left(\mathrm{t}_{\mathrm{f}} / \mathrm{h}\right)}{\mathrm{E}_{\mathrm{S}}}$

where:

$\mathrm{a}_{\mathrm{B}}\left(\mathrm{h}, \mathrm{t}_{\mathrm{f}}\right)=\frac{\pi \mathrm{a}_{0}}{\pi \mathrm{a}_{0}+2 \mathrm{t}_{\mathrm{f}}} \cong \frac{\pi \mathrm{h} \tan (\psi)}{\pi \mathrm{h} \tan (\psi)+2 \mathrm{t}_{\mathrm{f}}}$.

The extension of the model to multilayer coatings requires that:

$\mathrm{x}_{\mathrm{v}}{ }^{(1)}=1-\frac{\left.\pi \mathrm{h}-\frac{\mathrm{t}_{\mathrm{f}}^{(1)}}{100}\right) \tan (\psi)}{\left.\pi \mathrm{h}-\frac{\mathrm{t}_{\mathrm{f}}^{(1)}}{100}\right) \tan (\psi)+2 \mathrm{t}_{\mathrm{f}}} \quad$ if $\mathrm{h}>\frac{\mathrm{t}_{\mathrm{f}}^{(1)}}{100} \quad$ and

$$
\begin{aligned}
\mathrm{x}_{\mathrm{v}}{ }^{(\mathrm{j})}= & \left\{1-\frac{\left.\pi \mathrm{h}-\frac{1}{100} \sum_{\mathrm{i}=1}^{\mathrm{j}} \mathrm{t}_{\mathrm{f}}{ }^{(\mathrm{i})}\right) \tan (\psi)}{\left.\pi \mathrm{h}-\frac{1}{100} \sum_{\mathrm{i}=1}^{\mathrm{j}} \mathrm{t}_{\mathrm{f}}{ }^{(\mathrm{i})}\right) \tan (\psi)+2 \mathrm{t}_{\mathrm{f}}}\right\}- \\
& \left\{1-\frac{\left.\pi \mathrm{h}-\frac{1}{100} \sum_{\mathrm{i}=1}^{\mathrm{j}-1} \mathrm{t}_{\mathrm{f}}{ }^{(\mathrm{i})}\right) \tan (\psi)}{\left.\pi \mathrm{h}-\frac{1}{100} \sum_{i=1}^{\mathrm{j}-1} \mathrm{t}_{\mathrm{f}}{ }^{(\mathrm{i})}\right) \tan (\psi)+2 \mathrm{t}_{\mathrm{f}}}\right\} \text { if } \mathrm{h}>\frac{1}{100} \sum_{\mathrm{i}=1}^{\mathrm{j}} \mathrm{t}_{\mathrm{f}}{ }^{(\mathrm{i})}
\end{aligned}
$$

$\frac{1}{E_{C}}=\sum_{i=1}^{N} \frac{x_{v}^{(i)}}{E_{F}^{(i)}}+\frac{x_{v}{ }^{(S)}}{E_{S}}$.

The model requires the determination of $\mathrm{N}+1$ parameters.

\section{References}

[1] D.G. Liu, J.P. Tu, C.D. Gu, R. Chen, C.F. Hong, Tribological and mechanical behaviors of TiN/CNx multilayer films deposited by magnetron sputtering, Thin Solid Films 519 (2011) 4842.

[2] T. Mori, M. Noborisaka, T. Watanabe, T. Suzuki, Oxidation resistance and hardness of TiAlSiN/CrAlYN multilayer films deposited by the arc ion plating method, Surf. Coat Technol. 213 (2012) 216.

[3] Z.G. Yuan, J.F. Yang, Z.J. Cheng, X.P. Wang, Q.F. Fang, Preparation and characterization of the Mo(C)N/Mo(C) multilayer coating, Surf. Coat. Technol. 231 (2013) 14. 
[4] W. Yongqiang, Z. Xiaoya, W. Zhongzhen, T. Xiubo, G. Chunzhi, Y. Shiqin, J. Zhiqiang C. Liangji, Effects of modulation ratio on microstructure and properties of TiN/TiAlN multilayer coatings, Surf. Coat. Technol. 229 (2013) 191

[5] Y. Zhang, Y. Zhai, F. Li, S. Zhang, P. Zhang, S. Zhang, Effect of microstructure and mechanical properties difference between sub-layers on the performance of alternate hard and soft diamond-like carbon multilayer films, Surf. Coat. Technol. 232 (2013) 575.

[6] M. Wen, H. Huang, K. Zhang Q Meng X. Li, L. Kong C. Hu, W. Zheng, The AlN laye thickness dependent coherent epitaxial growth, stress and hardness in NbN/AlN nanostructured multilayer films, Surf. Coat. Technol. 235 (2013) 367.

[7] J.B. Cai, X.L. Wang, W.Q. Bai, D.H. Wang, C.D. Gu, J.P. Tu, Microstructure, mechanical and tribological properties of a-C/a-C:Ti nanomultilayer film, Surf. Coat. Technol. 232 (2013) 403.

[8] C. Tritremmel, R. Daniel, H. Rudigier, P. Polcik, C. Mitterer, Mechanical and tribological properties of Al-Ti-N/Al-Cr-B-N multilayer films synthesized by cathodic arc evaporation, Surf. Coat. Technol. 246 (2014) 57.

[9] R.L. Schoeppner, N. Abdolrahim, I. Salehinia, H.M. Zbib, D.F. Bahr, Elevated temperature dependence of hardness in tri-metallic nano-scale metallic multilayer systems, Thin Solid Films 571 (2014) 247.

[10] J.J. Roa, E. Jiménez-Piqué, R. Martínez, G. Ramírez, J.M. Tarragó, R. Rodríguez, L. Llanes, Contact damage and fracture micromechanisms of multilayered TiN/CrN coatings at micro- and nano-length scales, Thin Solid Films 571 (2014) 308.

[11] W.Q. Bai, J.B. Cai, X.L. Wang, D.H. Wang, C.D. Gu, J.P. Tu, Mechanical and tribological properties of a-C/a-C:Ti multilayer films with various bilayer periods, Thin Solid Films 558 (2014) 176.

[12] M. Azadi, A. Sabour Rouhaghdam, S. Ahangarani, H.H. Mofidi, Mechanical behavior of TiN/TiC multilayer coatings fabricated by plasma assisted chemical vapor deposition on AISI H13 hot work tool steel, Surf. Coat. Technol. 245 (2014) 156.

[13] A. Leyland, A. Matthews, On the significance of the H/E ratio in wear control: a nanocomposite coating approach to optimised tribological behaviour, Wear 246 (2000) 1.

[14] J. Musil, F. Kunc, H. Zeman, H. Poláková, Relationships between hardness, Young's modulus and elastic recovery in hard nanocomposite coatings, Surf. Coat. Technol. 154 (2002) 304

[15] Yin-Yu. Chang, Shun-Jan Yang, Wu. Weite, Yu.-C.hu. Kuo, Jyh-Wei Lee, Chaur-Jeng Wang, Mechanical properties of gradient and multilayered TiAlSiN hard coatings, Thin Solid Films 517 (2009) 4934

[16] Y.-Y. Chang, C.-J. Wu, Mechanical properties and impact resistance of multilayered TiAlN/ZrN coatings, Surf. Coat. Technol. 231 (2013) 62

[17] H. Gao, C.H. Chiu, J. Lee, Elastic contact versus indentation modeling of multi-layered materials, Int. J. Solids Struct. 29 (1992) 2471.

[18] J. Menčík, D. Munz, E. Quandt, E.R. Weppelmann, M.V. Swain, Determination of elastic modulus of thin layers using nanoindentation, J. Mater. Res. 12 (1997) 2475.

[19] A. Perriot, E. Barthel, Elastic contact to a coated half-space: effective elastic modulus and real penetration, J. Mater. Res. 19 (2004) 600

[20] J.M. Antunes, J.V. Fernandes, N.A. Sakharova, M.C. Oliviera, L.F. Menezes, On the determination of the Young's modulus of thin films using indentation tests, Int. J. Solids Struct. 44 (2007) 8313

[21] A.M. Korsunsky, A. Constantinescu, The influence of indenter bluntness on the apparent contact stiffness of thin coatings, Thin Solid Films 517 (2009) 4835.

[22] M.F. Doerner, W.D. Nix, A method for interpreting the data from depth-sensing indentation instruments, J. Mater. Res. 1 (1986) 601.

[23] S. Bec, A. Tonck, J.M. Georges, E. Georges, J.L. Loubet, Improvements in the indentation method with a surface force apparatus, Philos. Mag. A 74 (5) (1996) 1061.

[24] S.J. Bull, Mechanical response of atomic layer deposition alumina coatings on stiff and compliant substrates, J. Vac. Sci. Technol. A30 (2012) 01A160.

[25] S.J. Bull, A simple method for the assessment of the contact modulus for coated systems, Philos. Mag. (2014)http://dx.doi.org/10.1080/14786435.2014.909612.
[26] R. Whiting, M.A. Angadi, Young modulus of thin films using a simplified vibrating reed method, Meas. Sci. Technol. 1 (1990) 662

[27] R. Whiting, M.A. Angadi, S. Tripathi, Evaluation of elastic moduli in thin-film substrate systems by the two-layer vibrating reed method, Mater. Sci. Eng. B 30 (1995) 35.

[28] U. Harms, L. Kempen, H. Neuhäuser, Vibrating reed apparatus with optical detection and digital signal processing: application to measurements on thin films, Rev. Sci. Instrum. 70 (1999) 1751.

[29] T. Chudoba, N. Schwarzer, F. Richter, U. Beck, Determination of mechanical film properties of a bilayer system due to elastic indentation measurements with a spherical indenter, Thin Solid Films 377-378 (2000) 366.

[30] J. Malzbender, R.W. Steinbrech, Mechanical properties of coated materials and multi-layered composites determined using bending methods, Surf. Coat. Technol. 176 (2) (2003) 165.

[31] A. López-Puerto, F. Avilés, F. Gamboa, A.I. Oliva, A vibrational approach to determine the elastic modulus of individual thin films in multilayers, Thin Solid Films 565 (28) (2014) 228.

[32] K. Rahmoun, A. Iost, V. Keryvin, G. Guillemot, N.E. Chabane Sari, A multilayer model for describing hardness variations of aged porous silicon low-dielectric-constant thin films, Thin Solid Films 518 (2009) 213.

[33] A.M. Korsunsky, M.R. McGurk, S.J. Bull, T.F. Page, On the hardness of coated systems, Surf. Coat. Technol. 99 (1998) 171.

[34] B. Jönsson, S. Hogmark, Hardness measurements of thin films, Thin Solid Films 114 (1984) 257.

[35] T. Chudoba, N. Schwarzer, F. Richter, Steps towards a mechanical modeling of layered systems, Surf. Coat. Technol. 154 (2002) 140

[36] F. Cleymand, O. Ferry, R. Kouitat, A. Billard, J. von Stebut, Influence of indentation depth on the determination of the apparent Young's modulus of bi-layer material: Experiments and numerical simulation, Surf. Coat. Technol. 200 (2005) 890.

[37] D. Chicot, E.S. Puchi-Cabrera, R. Aumaitre, G. Bouscarrat, C. Dublanche-Tixier, F. Roudet, M.H. Staia, Elastic modulus of TiHfCN thin films by instrumented indentation, Thin Solid Films 522 (2012) 304.

[38] M. Jarratt, J. Stallard, N.M. Renevier, D.G. Teer, An improved diamond-like carbon coating with exceptional wear properties, Diam. Relat. Mater. 12 (2003) 1003.

[39] M.H. Staia, E.S. Puchi Cabrera, A. Iost, A. Zairi, S. Belayer, A. Van Gorp, Tribological response of AA 2024-T3 aluminium alloy coated with a DLC duplex coating, Tribol. Int. 85 (2015) 74-87.

[40] W.C. Oliver, G.M. Pharr, Measurement of hardness and elastic modulus by instrumented indentation: advances in understanding and refinements to methodology, J. Mater. Res. 19 (2004) 3.

[41] M.H. Staia, E.S. Puchi-Cabrera, A. Iost, E. Carrasquero, Y.Y. Santana Mendez, J.G. La Barbera Sosa, D. Chicot, A. Van Gorp, Sliding wear of a-C:H coatings against alumina in corrosive media, Diam. Relat. Mater. 38 (2013) 139.

[42] Y. Lia, Y. Gao, B. Xiao, T. Min, Y. Yang, S. Ma, D. Yi, The electronic, mechanical properties and theoretical hardness of chromium carbides by first-principles calculations, J. Alloys Compd. 509 (2011) 5242

[43] H. Faraoun, H. Aourag, C. Esling, J.L. Seichepine, C. Coddet, Elastic properties of binary $\mathrm{NiAl}, \mathrm{NiCr}$ and $\mathrm{AlCr}$ and ternary $\mathrm{Ni}_{2} \mathrm{AlCr}$ alloys from molecular dynamic and Abinitio simulation, Comput. Mater. Sci. 33 (2005) 184

[44] A. Yoshida, M. Fujii, Influence of soft surface modification on rolling contact fatigue strength of machine element, Tribol. Int. 35 (2002) 837.

[45] P. Lemoine, J.P. Quinn, P.D. Maguire, J.A. McLaughlin, Mechanical characterisation and properties of DLC films, in: C. Donnet, A. Erdemir (Eds.), Tribology of Diamond-like Carbon Films, Fundamentals and Applications, Springer Science and Business Media, LLC 2008, p. 83.

[46] M. Andersson, J. Högström, S. Urbonaite, A. Furlan, L. Nyholm, U. Jansson, Deposition and characterization of magnetron sputtered amorphous $\mathrm{Cr}-\mathrm{C}$ films, Vacuum 86 (2012) 1408. 